\title{
WestVirginiaUniversity
}

THE RESEARCH REPOSITORY @ WVU

Graduate Theses, Dissertations, and Problem Reports

2010

\section{The role of autonomy in suicidal ideation among older adults}

Alisa A. O'Riley

West Virginia University

Follow this and additional works at: https://researchrepository.wvu.edu/etd

\section{Recommended Citation}

O'Riley, Alisa A., "The role of autonomy in suicidal ideation among older adults" (2010). Graduate Theses, Dissertations, and Problem Reports. 3109.

https://researchrepository.wvu.edu/etd/3109

This Dissertation is protected by copyright and/or related rights. It has been brought to you by the The Research Repository @ WVU with permission from the rights-holder(s). You are free to use this Dissertation in any way that is permitted by the copyright and related rights legislation that applies to your use. For other uses you must obtain permission from the rights-holder(s) directly, unless additional rights are indicated by a Creative Commons license in the record and/ or on the work itself. This Dissertation has been accepted for inclusion in WVU Graduate Theses, Dissertations, and Problem Reports collection by an authorized administrator of The Research Repository @ WVU.

For more information, please contact researchrepository@mail.wvu.edu. 
The Role of Autonomy in Suicidal Ideation among Older Adults

Alisa A. O’Riley, M.A.

\author{
Dissertation submitted to the \\ Eberly College of Arts and Sciences \\ at West Virginia University \\ in partial fulfillment of the requirements \\ for the degree of \\ Doctor of Philosophy \\ in \\ Clinical Psychology
}

Amy Fiske, Ph. D.

Kristina Curci, M.D.

Barry Edelstein, Ph.D.

William Fremouw, Ph.D.

JoNell Strough, Ph.D.

Department of Psychology

Morgantown, West Virginia

2010

Keywords: suicidal ideation, suicidal behavior, older adults, late life, autonomy Copyright 2010 Alisa A. O'Riley 


\begin{abstract}
The Role of Autonomy in Suicidal Ideation among Older Adults
\end{abstract}

\begin{abstract}
Alisa A. O’Riley
Although rates of death by suicide in older adults in the United States appear to be decreasing, older adults remain at higher risk for completed suicide than any other age group (Center for Disease Control, 2005). In looking at suicidal behavior in particular, several researchers (e.g. Caine \& Conwell, 2001) have suggested that one important way one might begin to understand risk factors for suicide in late life is to identify distal factors that put older adults at risk for suicidal behavior. This study explicitly set out to examine one possible distal risk factor. That is, a strong emphasis on autonomy. The notion that a strong emphasis on autonomy (which can be defined as a cluster of behaviors reflecting an excessive, perfectionistic value placed on achievement, control, and being separate from others; Bieling, Beck, \& Brown, 2004) may be a distal risk factor for depression was first posited by Beck, Epstein, and Harrison (1982) as part of Beck's cognitive theory of depression. Specifically, Beck and colleagues (1982) hypothesized that individuals who have a strong emphasis on autonomy might become depressed as a result of achievement-related stressors or stressors that threaten the individual's independence (this is termed the Congruency Hypothesis). Past research has demonstrated a relation between depression and a strong emphasis on autonomy in both younger and older adults. One study (O'Riley et al., 2008) demonstrated a relation between two subscales on a measure of autonomy (i.e. Defensive Separation and Excessive Perfectionism) and suicidal ideation in younger adults; however, these variables have not been examined in older adults. Thus, the present study set out to examine whether a strong emphasis on autonomy is related to suicidal ideation in older adults. In addition, several exploratory research questions were examined, including: 1) whether the different subscales of a commonly used measure of autonomy (i.e. Need for Control, Defensive Separation, and Excessive Perfectionism) predict suicidal ideation in older adults 2) whether the relation between a strong emphasis on autonomy and suicidal ideation in older adults is moderated by functional impairment 3) whether willingness to seek help mediated the relation between a strong emphasis on autonomy and suicidal ideation in older adults 4) whether a strong emphasis on autonomy would mediate the relation between gender and suicidal ideation in older adults and 5) whether a strong emphasis on autonomy would predict suicidal ideation in older adults even when controlling for depressive symptoms. In order to examine these research questions, 88 older adults (53\% male) were asked to complete a mailed paper and pencil survey, which included a measure of suicidal ideation, a measure of autonomy, a measure of functional impairment, and a measure of depressive symptoms. Results indicated that only need for control was a significant, positive predictor of suicidal ideation in older adults. No other hypotheses were supported. These findings are of interest because they suggest that the relation between a strong emphasis on autonomy and suicidal ideation may differ between younger and older adults. The results of this study provide important
\end{abstract}


information for the development or tailoring of prevention and intervention programs for suicidal behavior in late life. 
Autonomy and Suicidal Ideation in Older Adults iv

\section{DEDICATION}

William Maxwell wrote, "The suicide doesn't go alone, he takes everybody with him." This project is dedicated to anyone who has been affected by late life suicide. 


\section{ACKNOWLEDGEMENTS}

This project could not possibly have been completed without the persistent and dedicated efforts of innumerable others to whom I am eternally grateful.

First, I owe a very large debt of gratitude to Amy Fiske, my chair and advisor. No one in the history of dissertation making has had a better advisor for their project or their graduate career, for that matter. Amy has been the perfect model of everything that a truly great psychologist, researcher, supervisor, and mentor should be. I am so very proud to call myself Amy's student and everything good about this project is a direct reflection of her mentorship.

In addition, I would like to thank all of the members of the Mental Health and Aging Lab (past and present). Many members had a direct hand in assisting with this project and every member provided an invaluable sounding board for the ideas upon which this project was based. I am also more grateful than I can say for all of my labmates' support during my defense (no one should have to wait outside that room alone).

Next, I would like to thank my committee members: Kristina Curci, Barry Edelstein, William Fremouw, and JoNell Strough. Their input only improved this project.

I would also like to thank Daniel Segal. If not for Dan's influence, encouragement, and support during my undergraduate career and my master's program, I would never have entered into what I consider the best career in the world - clinical geropsychology. I will always be grateful that he converted me to the "dark side."

I also need to thank all my friends for their boundless support. I am continually amazed at how lucky I am to have all of them in my life. In particular, I would like to thank my intern class at the VA Palo Alto. How lucky I have been to go through internship with such a fabulous group of people. I would also like to thank all of my graduate school buddies and their spouses: Katie Brown, Tara Noecker, Clare Mehta, Brian Ayotte, Eric Goedereis, Kristina Goedereis, Rachel Detlor, Michael Ballisante, Renata Martins, Lucas Rosu, Matthew Goldfine, and Salvatore Insana. I can say definitively that I could not possibly have gotten through graduate school without them. Finally, I want to thank my oldest and closest friend, Nicole Bellefeuille. Nicole has been my confidant, cheerleader, and voice of reason for more years than I can count. She is also the only person I knew before graduate school who has never once questioned my decision to stay in school for so many years.

Finally, I want to thank my family. My parents, Donna O'Riley and Karl Dittmer, have given me one of the greatest gifts parents can give a child - the freedom to choose her own path - even when the choice I made meant being away for years. They have cheered every one of my successes and comforted me after every failure. My brother, Andy O'Riley, also deserves a great deal of gratitude for his support but also for the fact that he has often been my inspiration in hard times. My in-laws, Patricia Hannum and David Hannum, and my sister-in-law, Laura Hannum, also deserve my thanks for being 
supportive of me and also for putting up with the fact that I have dragged my husband all over the country. And, finally, my biggest thanks goes to my husband, Dave Hannum. He was there every step of the way, and he sacrificed a great deal so that I could reach my goal. Very few people would have put up with all I have put him through in the name of my career, but he never once doubted me and he never once complained (he even made me dinner a few hundred times). I will never know what I did to be worthy of such an extraordinary husband. 


\section{TABLE OF CONTENTS}

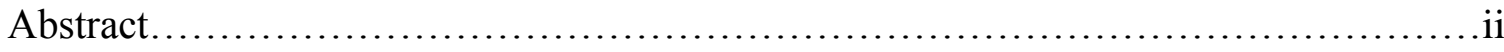

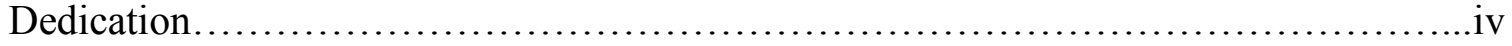

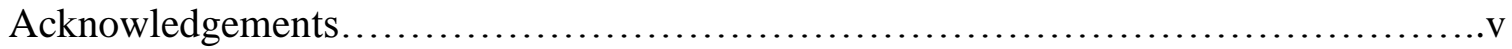

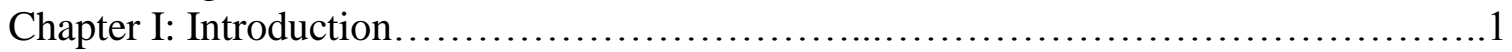

The Paradox of Aging ........................................................

Maintaining Well-being in Late Life by Shifting Control...........................

When Problems Occur in Late Life...........................................

Risk Factors for Suicide in Late Life Related to Control Strategies................5

The Present Study: Cognitive Styles as Possible Predictors of Problems in Late

Life................................................................... 7

Research Questions, Hypotheses, and Exploratory Research Questions............19

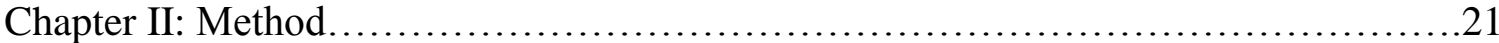

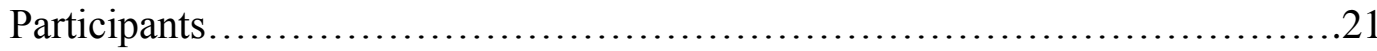

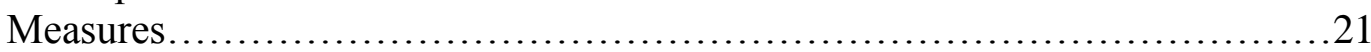

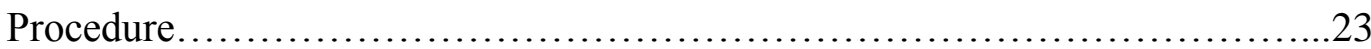

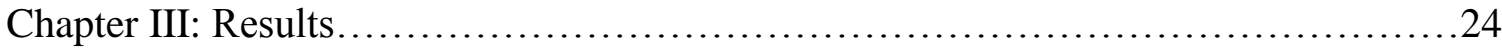

Missing Data Analyses..................................................

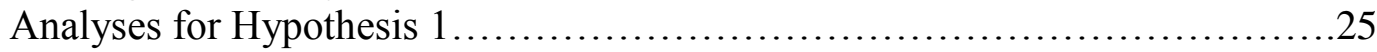

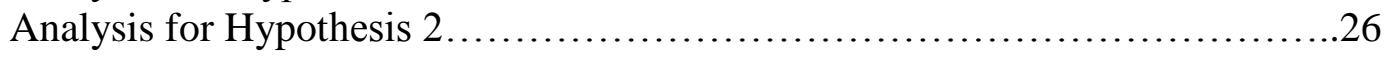

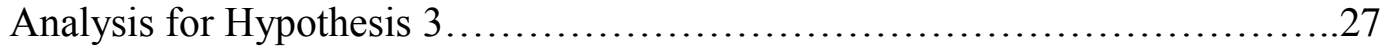

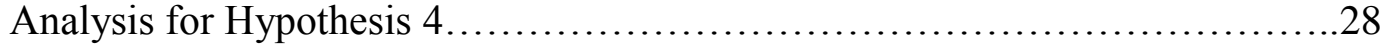

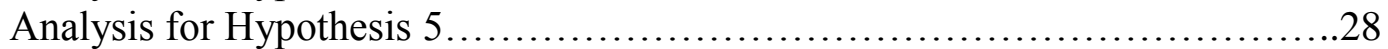

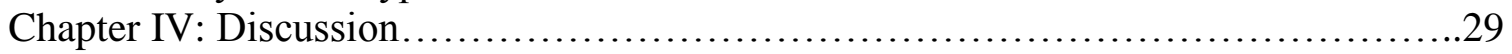

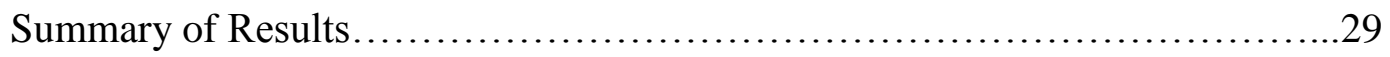

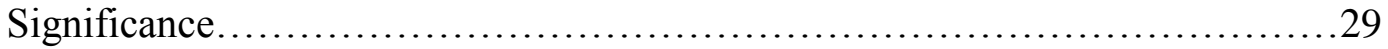

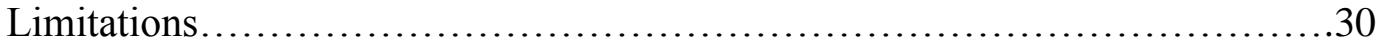

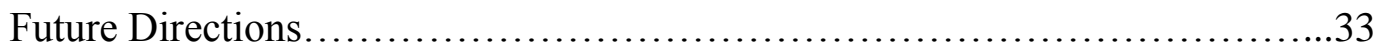

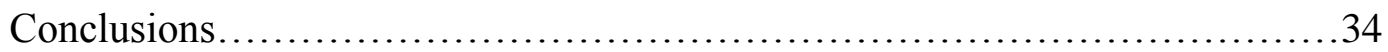

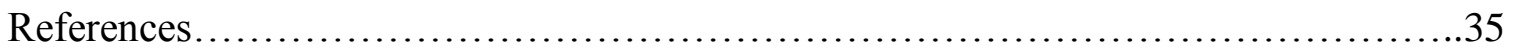

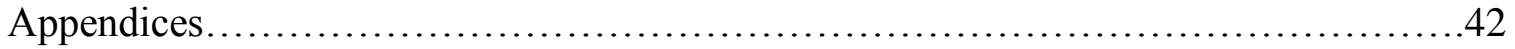

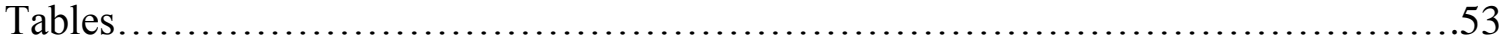

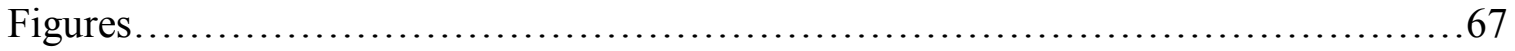




\section{CHAPTER I: INTRODUCTION}

The objective of the present study was to examine the possibility that cognitions regarding autonomy may be related to negative outcomes in late life. Autonomy has been proposed by several researchers as one of two "central value systems" that confers increased risk for depression (the other value system is sociotropy; Beck, Epstein, \& Harrison, p. 3, 1982). For the purposes of the present study, autonomy may be defined as a cluster of behaviors reflecting an excessive, perfectionistic value placed on achievement, control, and being separate from others (Bieling, Beck, \& Brown, 2004; Robins et al., 1994). Robins and colleagues (1994) suggested that these three values might lead to high levels of self-criticism, cognitive inflexibility, and maladaptive isolation. In particular, this study investigated whether factors on a measure of autonomy (i.e. need for control, defensive separation from others, and perfectionism) that have been shown to predict depressive symptoms might also predict suicidal ideation in older adults. The overarching goal of this study was to identify possible risk factors for negative outcomes in older adulthood that, ultimately, might facilitate the development or tailoring of prevention and intervention programs for suicidal behavior in late life.

\section{The Paradox of Aging}

Of all the developmental stages, older adulthood is marked by the most losses (Heckhausen, Dixon, \& Baltes, 1989). As people age, they are more and more likely to experience loss of loved ones, loss of health, and loss of functional ability. Research has demonstrated that individuals expect to experience loss as they age (Heckhausen et al.), and, when asked to consider these losses, they often report feeling anxious about the prospect of entering late life.

Yet, despite all of the losses common in late life, older adults in the United States and other western countries, over all, experience very good mental health. In the general population (aged 18 and older), 12-month prevalence of Major Depressive Disorder appears to be about $6 \%$ (e.g. Kessler et al., 2003). Although prevalence of depressive symptoms may be as high as $15 \%$ in community-dwelling older adults (65 and older; Blazer, 2003), prevalence of Major Depressive Disorder is in the range of 1-5\% (e.g. Hasin, Goodwin, Stinson, \& Grant, 2005). Longitudinal studies of affect suggest that negative affect decreases in late life and positive affect remains stable well into older adulthood (Charles, Reynolds, \& Gatz, 2001). Longitudinal investigations of psychological well-being and life satisfaction also indicate that older adults are at least as satisfied with their lives as younger adults (Diener \& Suh, 1997). The fact that older adults maintain good mental health despite the fact that they experience a great deal of loss has been termed the "paradox of aging" (Carstensen, Fung, \& Charles, 2003).

\section{Maintaining Well-being in Late Life by Shifting Control}

Several developmental theorists have posited explanations for how older adults are able to maintain well-being despite the losses they experience, but the theory that most 
directly speaks to this issue is the Motivational Theory of Life Span Development (MTLSD; Heckhausen \& Schulz, 1995; Heckhausen, Wrosch, \& Schulz, 2010). The MTLSD starts with the assumption that all human beings (and most other sentient beings) have an inherent desire to exert control over their environment (Heckhausen \& Schulz). The authors of this theory point out that even neonates prefer to get a reward after a response rather than getting a reward that is non-contingent on their behavior (Heckhausen \& Schulz). Based on this assumption, the theory posits two different mechanisms that allow humans to consistently maintain control over their environment. These mechanisms (originally identified by Rothbaum, Weisz, \& Snyder, 1982) are primary control and secondary control. According to MTLSD, primary control, or direct action on the environment, takes precedence over secondary control (Heckhausen \& Schulz; Heckhausen et al.). Secondary control, or action taken toward the self, facilitates primary control. Specifically, secondary control strategies serve the purpose of 1) helping the individual optimize goal selection 2) helping the individual optimize his or her expectancies about the outcome of the individual's actions 3) and, in the event of failure, helping the individual consider causal attributions and make inferences that will serve to both preserve the individual's self-esteem and sense of self-efficacy and, at the same time, increase the likelihood of success in the future (Heckhausen \& Schulz; Heckhausen et al.).

In order to better distinguish between primary and secondary control strategies, let us examine an example of a situation commonly faced in older adulthood. If one's goal is to maintain one's physical health for as long as possible, one might take several direct actions to work toward that goal (e.g. exercising regularly, getting examinations from one's physician, eating healthily, etc). These actions would be primary control strategies. At the same time, one would also likely utilize different secondary control strategies depending on what phase of action one was in in terms of one's goal (Heckhausen \& Schulz, 1995; Heckhausen et al., 2010). During the first phase of working toward one's goal (predecisional motivation phase), one would likely carefully weigh the pros and cons of the different primary control strategies one could possibly engage in in order to meet one's goal. If one is a normal healthy adult, one would likely place a higher value on strategies that one believed to be more accessible (e.g. one might place more value on eating healthily, knowing that one might reach a point at which exercise will be too difficult due to functional health declines). Also at this phase, one might carefully moderate one's expectations of success in one's goal, knowing that many older adults are unable to maintain good health even when they engage in primary control strategies due to circumstances outside of their control. During the next phases of working toward one's goal (the preactional and actional phases), one might use cognitive secondary control strategies such as selective attention and preferential encoding of action-relevant information to increase one's ability to successfully engage in primary control strategies. Lastly, during the final phase of working toward one's goal (postactional processing), one would use secondary control strategies to consider causal attributions for the outcomes of one's primary control behaviors. Ideally, these causal attributions would serve to maintain one's self-efficacy and self-esteem no matter what the outcome (i.e. if one succeeded, an adaptive secondary control behavior would be to believe that one's success was a reflection of one's positive qualities, and, if one failed, an adaptive secondary 
control behavior might be to attribute one's failure to a situation outside of one's control) so that one will engage in more primary control behaviors in the future.

According to the MTLSD, the ability to create goals and to engage in primary control behaviors that are designed to bring one closer to one's goals is contingent upon different constraints across the life-span (Heckhausen \& Schulz, 1995; Heckhausen et al., 2010; Wrosch, Schulz, \& Heckhausen, 2004). Working within these constraints, the best outcomes will be associated with first selecting goals that are developmentally appropriate (Heckhausen \& Schulz; Heckhausen et al.). Second, the theory suggests that, in order to have optimal outcomes, one must engage in behaviors that move one closer to the desired goal. If, however, one meets with failure or the goal is unattainable, the theory suggests that one can best adapt by disengaging from the goal in a way that maintains feelings of self-efficacy and good self-esteem (Heckhausen \& Schulz; Heckhausen et al.).

Given this model, the developmental trajectory of aging would suggest that, due to physical illness and functional impairment, it becomes more and more difficult to successfully engage in primary control strategies in older adulthood, and older adults must compensate by increasing secondary control striving (please see Figure 1 for a graphic representation of this developmental trajectory). If they are able to make adaptive use of secondary control behaviors, they will continue to attempt primary control behaviors, even in the face of past failures (this is, according to MTLSD, the definition of successful aging).

Heckhausen and colleagues have conducted several studies testing various tenets of MTLSD. For example, a cross-sectional study examining the use of different control behaviors in younger and old adults demonstrated that, in fact, primary control striving is maintained across the lifespan and secondary control striving actually increases with age (Heckhausen, 1997). Examinations of longitudinal data also support the notion that the use of secondary control strategies increases once individuals reach older adulthood (Haynes, Heckhausen, Chipperfield, Perry, \& Newall, 2009; Wrosch, Schulz, \& Heckhausen, 2002). Additionally, longitudinal research suggests that, although the importance of primary control behaviors does not change as individuals age, the types of primary control behaviors might change for certain individuals. Specifically, some individuals appear to engage in more compensatory primary control behaviors as they age (e.g. asking for help for tasks one can no longer do; Haynes et al., 2009).

Finally, longitudinal research has also demonstrated that failure to engage in health related primary control strategies and secondary control strategies designed to improve the success of health related primary control strategies significantly predicts depressive symptoms in older adults one year later $\left(R^{2}=.37\right.$; Wrosch et al., 2002). Conversely, it also appears that having high levels of depressive symptoms significantly predicts less engagement in primary control strategies one year later as well $\left(R^{2}=.05\right.$; Wrosch et al.). These findings suggest that the relation between engaging in primary control strategies and depressive symptoms is transactional. 


\section{When Problems Occur in Late Life}

Overall, it appears that most older adults are able to cope with losses by changing the types of primary control behaviors in which they engage and increasing the use of secondary control strategies (Heckhausen et al., 2010). At the same time, however, there also appears to be a subset of older adults who do not successfully cope with aging (Fiske, Wetherell, \& Gatz, 2009; Wrosch et al., 2002). It is absolutely imperative that clinicians gain a better understanding of the factors that lead this group of older adults to "go off course" developmentally, because, for a small group of these individuals, an inability to cope with the losses associated with aging may be fatal.

Although rates of death by suicide in older adults in the United States appear to be decreasing, older adults remain at higher risk for completed suicide than any other age group (Center for Disease Control, 2005). In fact, older adults make up $12.4 \%$ of the population but account for more than $16 \%$ of all deaths by suicide. An older adult commits suicide every 101 minutes in the United States. Data suggest that older white men, in particular, are at highest risk for suicide (CDC, 2005). Significantly, up to $85 \%$ of older adults who commit suicide suffer from significant symptoms of depression (Conwell \& Brent, 1996). The finding that suicide in older adults is related to depression is particularly tragic because research has demonstrated that older adults respond quite well to treatments for depression (Scogin, Welsh, Hanson, Stump, \& Coates, 2005). Thus, prevention of older adult suicide is theoretically possible. In order to prevent suicide in older adults, however, a better understanding of why certain individuals do not successfully navigate the pitfalls of aging is needed.

Because the majority of older adults who die by suicide are depressed (Conwell \& Brent, 1996), it seems reasonable to take note of models of late life depression as a way of better understanding how someone might eventually die by suicide. Figure 2 presents a behavioral model of onset and maintenance of late life depression recently developed by Fiske and colleagues (2009). In this model, stressful life events and/or physical declines might lead someone with certain long-standing vulnerabilities to begin limiting his or her activities. In a traditional behavioral model of depression, limiting activities is problematic because it results in fewer opportunities for interactions with the environment that have positive outcomes. A lack of positive interactions might result in depression. Depression might lead to in an increase in self-critical cognitions, which might provide a rationale for not engaging in future activities and a vicious cycle develops. Of particular interest is the overlap between this model and the results of studies examining aspects of the MTLSD. As was noted earlier, empirical studies of the MTLSD have demonstrated that engaging in fewer primary control behaviors (i.e. limiting one's activities) predicts level of depression a year later (Wrosch et al., 2002). The model developed by Fiske and colleagues (2009) adds to one's understanding of dysfunction in older adulthood in that it presents the theory that depression in late life results when certain distal, long-standing vulnerabilities interact with more proximal stressors to begin the vicious cycle that occurs when one stops engaging in primary control strategies. 
This behavioral model of late life depression is very similar to a model of late life suicide developed by Caine and Conwell (2001). Figure 3 presents a graphic illustration of Caine and Conwell's model. In this model, a variety of very distal risk factors (listed under targets for prevention) interact with more individually-based risk factors (listed under targets for intervention) to create risk for death by suicide in late life.

As is conceptualized within both the model for late life depression developed by Fiske and colleagues (2009) and the model for late life suicide developed by Caine and Conwell (2002), a key to preventing negative developmental outcomes in late life is the identification of distal risk factors (or long-standing vulnerabilities) that might make it difficult for individuals to navigate the key developmental task in older adulthood. The next section will focus on discussing some known risk factors for suicidal behavior in late life. In addition, some hypotheses are presented about how these risk factors might relate to negative outcomes in older age as it is conceptualized in the MTLSD.

\section{Risk Factors for Suicide in Late Life Related to Control Strategies}

The following section will review several possible long-standing (or distal) characteristics that may be risk factors for suicidal behaviors in late life. Several different possible characteristics are examined.

Narcissism. One theory of late life suicide posits that a subset of older adults are unable to cope with normal age-related stressors due to a character flaw that is not evident until late life (Clark, 1993). Clark developed his theory based on a qualitative psychological autopsy of older adults who died by suicide. Psychological autopsy is a method, often used in suicide research, that involves assembling information from multiple sources on individuals who died, (e.g., via a thorough review of medical and psychiatric records, a thorough forensic examination, and structured interviews with family members, friends, and attending health care personnel who knew or worked with the deceased;Isometsä, 2001). In Clark's model, older adults who die by suicide are hypothesized to have a long-standing narcissistic character trait that centers on a need for control and independence. According to Clark, this form of narcissism is not evident earlier in life because it is actually adaptive in younger adults. That is, in young adulthood, being very independent might be rewarded. However, as individuals age, an excessive need for independence might make it very difficult to cope with stressors that require one to become dependent on others. Although this theory has not been empirically examined, some research has examined narcissism (both narcissistic traits and narcissistic personality disorder) in older adults who have been hospitalized for depression (Heisel, Links, Conn, van Reekum, \& Flett, 2007). In one study in particular, narcissism was a significant, positive predictor of suicidal ideation $(B=.36, S E=.01, p<$ $.05)$. Clark's theory of late life suicide has interesting implications for the MTLSD. It seems possible that, as individuals age, traits that once facilitated their success in primary control strategies might impede their ability to disengage from unattainable goals and make appropriate use of secondary control strategies. 
The Five Factor Model of Personality. Different personality traits might be other possible distal risk factors that may make individuals less able to negotiate the developmental tasks of late life. Duberstein and colleagues have done extensive work examining the relation between personality traits, measured with the NEO Five Factor Model (Costa \& McCrae, 1992), and suicidal behavior in older adults (Duberstein, Conwell, \& Caine, 1994; Duberstein, Conwell, Seidlitz, Denning, Cox, \& Caine, 2000; Heisel, Duberstein, Conner, Franus, Beckman, \& Conwell, 2006; Useda et al., 2007). The NEO Five Factor Model measures five personality traits. Extroversion is a trait characterized by high energy, positive emotions, and a tendency to seek stimulation in the company of others. Individuals low in Extroversion have a tendency to be quiet, low-key, and less involved in the social world (Costa \& McCrae). Neuroticism is a trait characterized by the experience of negative emotions such as anger, anxiety, and depressive symptoms. Low Neuroticism is characterized by less emotional reactivity (Costa \& McCrae). Openness to Experience is a trait characterized by a general appreciation for art, emotion, adventure, novel ideas, and a variety of experiences. Individuals low in Openness to Experience have a tendency to be conventional, inflexible, and to strongly adhere to tradition (Costa \& McCrae). Conscientiousness is a trait marked by a tendency to show self-discipline, dutifulness, and a tendency to focus on achievement. Individuals low in Conscientiousness have a tendency to be more spontaneous (Costa \& McCrae). Finally, Agreeableness is a tendency to be compassionate and cooperative. Individuals high in this trait tend to focus on social harmony, and individuals low in Agreeableness tend to place self-interest above getting along with others (Costa \& McCrae).

In one early study examining the relation between suicidal behavior and the NEO Five Factor Model of personality, Duberstein and colleagues (2000) compared depressed older adults $(50+)$ who were hospitalized for a suicide attempt $(N=34)$ to depressed older adults $(50+)$ who were hospitalized for depression $(N=47)$. The results of this study demonstrated that levels of Extroversion significantly, negatively predicted suicide attempts $(r=-.27, p<.05)$. Additionally, Neuroticism significantly, positively predicted suicide attempts $(B=.30, p<.05)$. In another similar study, Useda and colleagues (2007) compared a group of older adults $(50+)$ who died by suicide $(N=43)$ to a group of age and gender matched older adults $(50+)$ hospitalized after a suicide attempt $(N=60)$ on the NEO Five Factor traits. Results of this study indicated that suicide attempters scored significantly higher on Neuroticism $(M=112.5, S D=25.5)$ than individuals who died by suicide $\left(M=93.0, S D=29.9 ; R^{2}=.26\right)$. Results also demonstrated that older adults that died by suicide scored significantly higher on Conscientiousness $(M=124.2, S D=33.7)$ than older adults who made suicide attempts $\left(M=108.5, S D=29.0, R^{2}=.29\right)$. The results of these studies might have important implications for our understanding of dysfunction in older adulthood. First, it seems likely that the ability to effectively engage in the social environment (extroversion) might increase individuals' abilities to effectively engage in primary control strategies throughout the lifespan. In particular, it seems likely that being high in extroversion might lead to individuals being more effective at using compensatory primary control strategies (such as help seeking) when they are no longer able to engage in direct primary control behaviors. Second, it is logical to suggest that individuals who are high in neuroticism might find it more difficult to 
effectively engage in secondary control strategies (which often involve such behaviors as positive self-talk). Finally, it is possible that individuals with high levels of conscientiousness (which is often characterized by achievement focus) might find it difficult to disengage from goals that are unattainable.

Duberstein and colleagues have also demonstrated in a series of studies that levels of openness to experience appear to be related to serious suicidal behavior (Duberstein, 1996). In a study examining the relation between elements of the Five Factor Model and suicidal ideation in older adults $(N=134,50$ years old and older) who were hospitalized for depression, low levels of Openness to Experience was a significant, positive predictor of suicidal ideation $(B=.03, S E=.01, p<.05$; Heisel et al., 2006). Duberstein suggested that this finding might indicate that openness to experience indicates a willingness to think about suicide as an option. Interestingly, a study examining deaths by suicide demonstrated opposite results. In a psychological autopsy study examining 52 individuals who died by suicide, Duberstein and colleagues demonstrated that, first of all, older individuals who died by suicide were rated as significantly lower on the Aesthetics $(M=$ $14.00, S D=4.34)$ and the Action $(M=10.52, S D=3.81)$ subscales of the Openness to Experience subscale of the NEO than age matched controls $(M=16.04, S D=6.00$ and $M$ $=15.09, S D=4.53$, respectively) who did not die by suicide. Older individuals who died by suicide were also rated as being lower in the Fantasy $(M=13.96, S D=3.01)$ and the Actions $(M=10.52, S D=3.81)$ subscales of the Openness to Experience subscale of the NEO than younger adults $(M=17.21, S D=5.14$ and $M=13.82, S D=4.48$, respectively) who died by suicide. According to Duberstein, one possible explanation for this finding may be that individuals who are low in openness to experience may excessively value independence. This focus on independence might be particularly problematic in old age because functional impairments might preclude individuals' abilities to have this value met (Duberstein). If the individual is repeatedly thwarted from engaging in primary control strategies related to this value, depression and hopelessness might occur (Heckhausen et al., 2010). Similarly, it has been suggested that low openness to experience might denote inflexibility (Duberstein et al., 1994). Such inflexibility might prohibit individuals from disengaging from unattainable goals in an appropriate way (Heckhausen \& Schulz, 1995).

\section{The Present Study: Cognitive Style as a Possible Predictor of Aging}

One final possible risk factor for suicidal behavior that might help to explain dysfunction in late life is cognitive style. The notion that one's cognitive style might be related to distress, especially to depression, comes from Beck's cognitive theory of depression (Beck et al., 1982). In this model, the phenomena involved in cognitive theory are presented based on their level of proposed stability. Beck hypothesized that underlying most behaviors are what he called "central value systems" or "personality structures." Beck hypothesized that some individuals have a central value system that increases vulnerability to depression in three ways: 1) it predisposes the person to become depressed in the face of certain stimuli 2) it determines the pattern of depression and 3) it influences an individual's response to treatment. He hypothesized that there are two central value systems in particular that increase vulnerability to depression (Beck et al.). 
He called these two systems "sociotropy" and "autonomy." Sociotropy is defined as need for close relationships, interpersonal dependency, and concern about approval. Autonomy is defined as excessive perfectionism, need for control, and defensive separation from others. Autonomy, as a cognitive style, should be differentiated from the concept of autonomy in developmental research on human agency. Autonomy, as it relates to human agency, is an adaptive human behavior that facilitates one's ability to intentionally make things happen in one's environment (Bandura, 2001). Thus, autonomy as it is discussed in research on human agency, is the capacity to engage in what Heckhausen and colleagues (1989) have termed primary control strategies. Autonomy, as it is discussed in Beck's cognitive model of depression, reflects desire for perfection, control, and independence (Beck et al., 1982). Paradoxically, individuals with a very high desire for independence and control may actually behave in ways that limit their ability to influence their environment.

To explain the relation between central value systems and depression, Beck and colleagues (1982) suggested what has since been termed the congruency hypothesis. Beck hypothesized that individuals high in either sociotropy or autonomy might be differentially vulnerable to depression after experiencing different kinds of stressors. That is, individuals that are high in sociotropy might become depressed after experiencing interpersonal stressors, and individuals high in autonomy might become depressed after experiencing achievement-related stressors or stressors that threaten the individual's independence. Although these central value systems are considered "long-standing vulnerabilities," Beck believed that they were amenable to treatment (Beck et al., 1982).

In terms of explaining suicidal behavior in late life, we might hypothesize that the cognitive style Beck termed "autonomy" is of primary interest because it most closely relates to constructs of control and agency (Beck et al., 1982). Thus, it is possible that older adults who are high in autonomy might have more difficulty disengaging from goals that are unattainable, they might be less likely to use compensatory primary control strategies when direct strategies are not an option (e.g. seeking help for an activity one can no longer do for one's self), and they may be less likely to adaptively engage in secondary control strategies (such as positive self-talk). Thus, individuals high in autonomy might have particular difficulties with coping with losses associated with aging, and might eventually become depressed and suicidal as a result of their inability to cope. The next section will focus on examining issues of measurement, which will then be followed by a discussion of the evidence that autonomy is related to negative outcomes in older adults.

Issues of measurement. Before examining the evidence that autonomy is related to negative outcomes in older adults, it is important to discuss several issues of measurement related to this construct. At the present time, there are two instruments that measure autonomy (the SAS and the PSI), and different studies examining autonomy have used different instruments (Robins et al., 1994). Several researchers have expressed concern about at least one of the measures of autonomy currently in use (Coyne \& Whiffen, 1995; Robins et al, 1994). For example, Robins and colleagues (1994) have questioned the validity of the most commonly used measure of these two traits, the 
Sociotropy and Autonomy Scale (SAS; Beck, Epstein, Harrison, \& Emery, 1983). Robins and colleagues point out that the SAS is problematic because the Autonomy subscale of this measure is not related to depressive symptoms in the predicted manner (Robins, Block, \& Peselow, 1989). While it is true that a vulnerability trait measure that is too highly correlated with depression might be considered to be invalid because it is actually measuring depression instead of a factor that confers vulnerability to depression, it is also true that a variable that is hypothesized to increase an individual's vulnerability to depression needs to be somewhat correlated with depression in order to have good construct validity (Robins et al.). Robins and colleagues suggest that this problem with the construct validity of the Autonomy subscale of the SAS may be related to the fact that the items of the scale do not have good internal reliability (Robins et al.). Factor analyses have since demonstrated that autonomy, as it is measured by the SAS, has some items that relate to positive outcomes (i.e. they are negatively correlated with depressive symptoms) and some items that relate to negative outcomes (Bieling et al., 2004). In addition to this construct validity problem, Robins and colleagues question the validity of the SAS because many of the items do not independently measure either sociotropy or autonomy; that is, they measure both variables simultaneously even though the items are only scored on one scale or the other (Robins et al.). Given this, it is not surprising that the two factors are highly, positively correlated with one another.

The PSI-II was specifically developed to address some of the validity problems with the SAS (Robins et al., 1994). More specifically, the items of this measure were developed to optimize construct validity, internal consistency, and independence between the sociotropy and autonomy scales (Robins et al.). The development of the scale was completed in two phases. The first stage started with 60 items (30 for each scale). Although this first version of the PSI was highly reliable and showed some validity, Robins and colleagues decided to modify the scale slightly because the original version of the scale was more highly correlated with depressive symptoms than they desired. The final version of the PSI, the PSI-II, consisted of 40 items from the original PSI and 8 items that performed well in factor analyses and studies correlating the items with a measure of depressive symptoms (see Measures section for more information about the PSI-II; Robins et al.).

Unfortunately, although the PSI-II arguably has better validity than the SAS, numerous studies have examined autonomy using the SAS. Thus, many of the studies reviewed in the next sections may have measurement limitations.

Autonomy and depressive symptoms in younger adults. Because autonomy was originally conceptualized by Beck and colleagues (1982) as a risk factor for depression a great deal of research has been conducted examining the relation between autonomy and depressive symptoms.

The results of several early studies have suggested that autonomy does not significantly predict depression. In one early study (Robins, Block, \& Peselow, 1989), researchers examined the relation between autonomy, as it is measured on the SAS, and depressive symptoms in 80 participants receiving treatment for psychological concerns $(M$ age $=$ 
42). Results indicated that autonomy was not significantly associated with depressive symptoms $(r=-.10, p>.05)$. In a second study (Şahin, Ulusoy, \& Şahin, 1993) that examined the relation between the SAS autonomy subscale and depressive symptoms in 70 psychiatric inpatients $(M$ age $=28.23)$ and 189 university students $(M$ age $=21.07)$ in Turkey, autonomy was not significantly correlated with level of depressive symptoms $(r$ $=.03, p>.05)$. Additionally, level of autonomy was not significantly different between depressed participants $(M=78.48, S D=13.68)$, dysphoric participants $(M=80.00, S D=$ $11.57)$, and participants that did not have mood symptoms $(M=79.50, S D=11.69)$.

Another interesting study (Alford \& Gerrity, 1995), which did not find a significant relation between autonomy and depressive symptoms, set out to examine whether the relation between autonomy and symptoms of depression changes over time. In this study, 112 undergraduate students (no age reported) were administered the SAS and a measure of depressive symptoms at one time period and then readministered a depressive symptoms measure 4 weeks later. Results of this study indicated that autonomy was not significantly correlated with depressive symptoms at Time $1(r=.08, p>.05)$ and autonomy at Time 1 was also not significantly correlated with depressive symptoms at Time $2(r=.04, p>.05)$.

Finally, two studies that set out to examine Beck's congruency hypothesis also demonstrated null results. In the first study (Husky, Mazure, Maciejewski, \& Swendsen, 2007), 179 French undergraduate students $(M$ age $=19.5)$ were asked, initially, to complete the SAS. They were then given a Palm Pilot and asked to record whether they had experienced an achievement stressor and their current level of negative state affect at four different time periods for 7 consecutive days. Results of this study indicated, first of all, level of autonomy did not significantly predict depressed mood in daily life $\left(\gamma_{24}=-\right.$ $.003, S E,=.006, p>.05)$, and autonomy scores did not increase the impact of achievement stress on depressed mood $\left(\gamma_{24}=-.006, S E=.005, p>.05\right)$. In the second study, (Dasch, Cohen, Sahl, \& Gunthert, 2008), 170 university students (age range = 1820) were first asked to complete the PSI-II. Next, they were asked to complete a measure of common achievement related stressors and a measure of state sadness nightly for 10 nights. Results indicated that autonomy did not increase the impact of achievement stressors on state-dependent sadness $\left(\gamma_{14}=.006, S E=.002, p>.05\right)$.

All in all, these studies suggest that autonomy may not be related to depressive symptoms. The congruency hypothesis was also not supported in these studies. It is important to note some major limitations of these studies, however. First, most of these studies used the SAS as a measure of autonomy, which may have significant validity problems, especially in terms of autonomy (Robins et al., 1994). Second, some research suggests that using the sub factors of Autonomy is a more appropriate measure of the construct (need for control, perfectionism, and defensive separation; Bieling, Beck \& Brown, 2004). In addition, the studies that examined the congruency hypothesis had several major limitations. First, neither of these studies used depressive symptoms as an outcome variable (they used state-dependent negative mood instead), which is problematic because Beck's theory is centered on depression (which is different from transitory moods). Second, these studies did not utilize a clinical sample. This may be 
problematic because it is unclear if the results of these studies would actually generalize to the population most of interest (i.e. individuals with depression; Coyne \& Whiffen, 1995). Given these limitations, more examination of the literature was necessary.

In contrast to studies demonstrating that autonomy may not be related to depressive symptoms, several studies have shown a significant relation between these two variables. First, in the work that was done to create the PSI-II (Robins et al., 1994), autonomy was found to be significantly, positively correlated with depressive symptoms in a sample of 156 undergraduates (age not reported; $r=.27, p<.001$ ). In another study (Robins, Bagby, Rector, Lynch, \& Kennedy, 1997), 103 participants being treated in an outpatient clinic ( $M$ age 39.8) were administered a measure of autonomy and several measures of depression and depressive symptoms. The researchers then identified the specific items of depression in their instruments that they believed to be most related to autonomy based on Beck and colleagues' (1982) theory. They used these items to create a composite "autonomous depression" score. Results indicated that autonomy was significantly correlated with this depression score $(r=.37, p<.001)$, as was predicted. Fairbrother and Moretti (1998) conducted another study that examined the relation between autonomy and depression. In this study, a group of $28(M$ age $=37.5)$ clinically depressed individuals was recruited from an outpatient clinic, a group of 20 patients who were in remission from depression was also recruited from an outpatient clinic $(M$ age $=37.05)$, and a group of 20 control participants $(M$ age $=29.95)$ was recruited from the community. All of these individuals were administered the PSI-II and several measures of depression and other forms of psychopathology. Because the three groups were not found to differ significantly, the samples were ultimately combined. Results indicated that autonomy was a significant predictor of depression $(\beta=.25, p<.05)$. In a similar study, Sato and MacCann (2000) demonstrated that, in a sample of 293 undergraduate students $(M$ age $=19.65)$, autonomy as it is measured on the PSI-II, was significantly correlated with depressive symptoms $(r=.34, p<.05)$. In another study that utilized a clinical sample (Bagby et al., 2001), 176 patients in an outpatient clinic ( $M$ age $=39.10$ ) were administered the PSI-II and several of measures of depression prior to treatment. They were also administered measures of depression after treatment. In this study, autonomy was a significant predictor of level of depression after treatment $\left(R^{2}=.18, p<\right.$ .01). In a final study, Mongrain and Blackburn (2006) administered the PSI-II and measures of depressive symptoms and psychopathology to 190 graduate students ( $M$ age $=28$ ) with depressive symptoms who were recruited at a university outpatient clinic at the start of the study. They then readministered the measures of depressive symptoms and psychopathology 16 months later. They demonstrated that level of autonomy at Time 1 was a significant predictor of level of depressive symptoms at Time $2(r=.47, p<.001)$.

Several studies have found evidence to support Beck's congruency hypothesis. In one study (Hammen, Ellicott, Gitlin, \& Jamison, 1989), 22 participants who were being treated for unipolar depression $(M$ age $=42.7)$ and 25 participants who were being treated for bipolar disorder $(M$ age $=37.5)$ were initially administered measures of depression and the SAS after their mood symptoms were considered to be in remission. Next, they were contacted every month for six months and interviewed to assess if any major events had occurred in the intervening weeks. They were also readministered measures of 
depression. Results indicated that unipolar patients who were high in autonomy and who had also experienced more achievement-related stress during the 6 months of assessment were more likely to be symptomatic 6 months after their remission $(M=314.00, S D=$ 138.00) than individuals who were high in autonomy and who had experienced more interpersonal stressors $(M=36.6, S D=58.8)$. Interestingly, these results were not replicated in the group of patients who were treated for bipolar disorder. In another study that examined the congruency hypothesis (Robins, Hayes, Block, Kramer, \& Villena, 1995), 160 undergraduate students (age not reported) were administered the SAS, a measure of different types of life stressors, and several measures of depression and depressive symptoms. The participants were readministered this battery 6 weeks later. The results of this study indicated, first of all, that autonomy was significantly correlated with depression at Time $1(r=.25, p<.05)$ and Time $2(r=.31, p<.05)$. In addition, the interaction between autonomy and a high level of achievement-related stressors was also a significant predictor of depression at Time 2, even when controlling for depression at Time $1\left(s r^{2}=.05, p<.01\right)$. Interestingly, in this study, the interaction between autonomy and a high level of interpersonal stressors was also a significant predictor of depression at Time 2, even when controlling for level of depression at Time $1\left(s r^{2}=.05, p<.01\right)$.

In addition to studies providing support for a relation between autonomy and depression and for Beck's congruency hypothesis, a number of studies have found partial support for Beck's theory. In one study that only provides partial evidence for the relation between autonomy and depressive symptoms (Nelson, Hammen, Daley, Burge, \& Davila, 2001), 155 female high school students $(M$ age $=18.2)$ were assessed in terms of the sub factors of the Autonomy scale of the SAS and in terms of symptoms of depression and other psychopathology. Results indicated that only need for control was significantly correlated with depressive symptoms $(r=.22, p<.05)$.

Several studies that examined Beck's congruency hypothesis also demonstrated mixed results for a relation between autonomy, congruent life stressors, and autonomy. For example, Clark and Oates (1995) examined the relation between the sub factors of the Autonomy scale of the SAS (achievement, need for control, and preference for solitude), a measure of depressive symptoms, and a measure of life stressors in 94 undergraduate students $(M$ age $=19.94)$. The results of this study indicated, first of all, that preference for solitude was significantly correlated with depressive symptoms $(r=.22, p<.05)$. In addition, the interaction between preference for solitude and achievement related stressors was a significant predictor of symptoms of depression $(\beta=.22, p<.05)$, such that individuals who are high in preference for solitude and who had had contact with an achievement related stressor in the 12-months prior to this study had higher levels of depressive symptoms. In another examination of the congruency hypothesis (Mazure, Bruce, Maciejewski, \& Jacobs, 2000), 43 depressed patients recruited from an outpatient clinic $(M$ age $=39.3)$ and 43 age-, race-, and sex-matched controls $(M$ age $=40.2)$ were administered the sub factors of the SAS Autonomy scale, a measure of depression, and a measure of stressful events that asked participants to explore stressful events either 6months prior to the onset of their depression or (for controls) for the 6-months prior to the study. In this study, scores on the need for control sub factor were significantly different for patients with depression $(z$ score $=.42, S D=.87)$ and for comparison participants $(z$ 
score $=-.42, S D=.94)$; however the interaction between need for control and the experience of adverse achievement events was not a significant predictor of depression $\left(\chi^{2}=2.65, p>.05\right)$. Frewen and Dozis (2006) conducted another investigation of the congruency hypothesis. The researchers recruited 188 undergraduates $(M$ age $=18.51)$ and had them complete the PSI-II and a measure of depressive symptoms. At this time, they were also asked to identify several social, achievement, and independence goals. Six months later, the researchers readministered the measure of depressive symptoms and also added a measure of negative life events, the impact of those events, and questions assessing whether goals identified at Time 1 were attained. Results of this study indicated that, first of all, none of the sub factors of autonomy were associated with depressive at Time 2. However, even after controlling for depressive symptoms at Time 1, defensive separation and perfectionism were negatively correlated with the attainment of social goals $(r=-.23, p<.05$ and $r=-.21 p<.05$, respectively). Additionally, perfectionism was positively correlated with the impact of negative social events $(r=.32, p<.05)$, failure-related events $(r=.34, p<.05)$, and independence-restricting events $(r=.25, p<$ $.05)$. Finally, need for control was positively correlated with the impact of negative independence-restricting events $(r=.18, p<.05)$. In a final study, the congruency hypothesis was examined using a prospective methodology (Iacoviello, Grant, Alloy, \& Abramson, 2009). In this study, 5,378 freshmen were administered several screening questionnaires, including the SAS and measures of depressive symptoms. Participants were further assessed if they did not meet criteria for psychopathology at the time of the screening instruments (they were retained in the study if they had previously had a depressive episode, if their depression was remitted for at least 2 months). Participants were then given several instruments, including a measure of depressive symptoms and a measure of stressful events, every 6 weeks for 2.5 years. During data collection, 156 participants $(M$ age $=18.7$ at onset of study) experienced at least one episode of depression during the course of this study and these individuals were the focus of the study conducted by Iacoviello and colleagues. Results of this study indicated that levels of autonomy at Time 1 and the interaction between autonomy and achievement-related stressors did not significantly predict the duration or chronicity of episode(s) of depression; however, both autonomy $(\beta=.16, p<.05)$ and the interaction between autonomy and achievement-related stressors $(\beta=.16, p<.05)$ predicted severity of depressive episode(s), such that individuals high in autonomy who experienced achievement-related stressors had more severe depressive episode(s).

Although a handful of studies seem to suggest that there is not a significant relation between depressive symptoms and autonomy in younger adults, there are numerous studies suggesting that autonomy is correlated with depressive symptoms in younger adults. There is also some evidence to suggest that autonomy may predict depressive symptoms in younger adults. Finally, there also seems to be some support for the hypothesis that individuals who are high in autonomy are more likely to have depressive symptoms if they have also experienced a stressor that is congruent with autonomy. In addition to examining the evidence about a relation between autonomy and depressive symptoms, however, it is also important to examine the literature about the relation between autonomy, depressive symptoms, and other possible mediating and moderating variables (such as gender and age). Finally, because the focus of the present study is on 
suicidal behavior as a negative outcome that may result when older adults with certain other risk factors are not able to effectively adapt to the stressors common in late-life, it will also be important to examine the literature on the relation between autonomy and suicidality.

Autonomy and gender. When Beck and colleagues initially developed the constructs of sociotropy and autonomy they hypothesized that women would have higher rates of sociotropy and men would have higher rates of autonomy (1982). Unfortunately, however, the research to date has not entirely supported Beck and colleagues' hypothesis that men and women would have different levels of sociotropy and autonomy. During the course of the current literature review, several studies which examined the relation between autonomy and gender were found. Several studies have found no gender differences between sociotropy and autonomy. For example, in a study examining sociotropy and autonomy in college students $(M$ age $=18.3)$ using the SAS, Zuroff and Fitzpatrick (1995) found that men $(M=84.50, S D=13.32)$ and women $(M=82.55, S D=$ 15.00) did not have significantly different levels of autonomy. In another study (Clark, Steer, Haslam, Beck, \& Brown, 1997) examining the SAS in 2,067 depressed outpatients ( $M$ age not reported), results indicated that the percentage of male depressed outpatients who were high in autonomy (10\%) did not significantly differ from the percentage of female depressed outpatients who were high in autonomy (9\%). One interesting study set out to examine the opposite of Beck's congruency theory (Campbell \& Kwon, 2001) in both men and women. In this study, 232 undergraduate students $(M$ age $=19.32)$ were administered the PSI-II, measures of psychopathology, and measures of domain specific hope. The researchers hypothesized that achievement-related hope would moderate the relation between autonomy and depressive symptoms, such that having high levels of autonomy would be less depressogenic in individuals who also have high levels of achievement-related hope. They found that, overall, autonomy was correlated with depressive symptoms $(r=.31, p<.05)$. They also found that the three-way interaction between autonomy, achievement hope, and gender was a significant predictor of depressive symptoms $(\beta=-.15, p<.01)$. Post hoc analyses demonstrated that, for men both the main effects of autonomy and achievement-related hope were significant predictors of depressive symptoms, but the interaction was not significant. For women, however, achievement-related hope buffers against depressive symptoms in individuals high in autonomy. The authors suggested that these findings might be related to the fact that women who are high in autonomy who place a high level of importance on achievement-related goals need a high level of achievement-related hope to prevent depression, because they are going against traditional gender roles (which would dictate that women focus on affiliation-related rather than achievement-related goals). Men who are high in autonomy who place importance on achievement-related goals may not need achievement-related hope as much because their goals are congruent with gender norms. In a fifth study, sex differences in the SAS sub factors of autonomy were examined in 43 participants who were being treated in an outpatient clinic $(M$ age $=39.3)$ and 43 agerace- and gender-matched controls ( $M$ age $=39.3$; Mazure et al., 2000). Results indicated that only the Need for Control subscale of Autonomy predicted depression $\left(\chi^{2}=9.44, p<\right.$ $.05, O R=3.90$ ). Gender did not significantly moderate this relation (Mazure \& Maciejewski, 2003b). As was noted earlier, because of validity problems with the SAS, it 
is also important to examine gender differences in autonomy as it is measured on the PSIII. One study examined sex differences in autonomy in undergraduate college students $(M$ age $=19.65)$ using both the SAS and the PSI-II (Sato \& McCann, 2000). This study demonstrated that men $(M=45.50, S D=6.66)$ and women $(M=43.99, S D=7.53)$ did not significantly differ on autonomy as it is measured by the SAS; however, on the PSIII, men $(M=83.44, S D=10.63)$ scored significantly higher on autonomy than women ( $M$ $=79.87, S D=11.15$ ). In another study which examined the PSI-II (Hong, Malik, \& Lee, $2003)$ in Korean undergraduate students $(M$ age $=21.8)$, however, women were found to have significantly higher levels of autonomy than men (Cohen's $d=.27$ ). Finally, two studies using the PSI-II have shown no sex differences in autonomy. During the initial development of the PSI-II, Robins and colleagues (1994) found no significant gender differences in levels of autonomy for either a sample of undergraduate students (no $M$ age reported) or a sample of outpatients seeking treatment for depression (age range $=25-70$ ). Similarly, in another study examining autonomy as it is measured by the PSI-II in depressed adults $(M$ age $=39.4$; McBride, Bacchiochi, \& Bagby, 2005), women's autonomy scores $(M=92.58, S D=17.95)$ did not significantly differ from men's autonomy scores $(M=95.28, S D=13.72)$.

Overall, the results of studies examining gender differences in autonomy are mixed. It appears that, when the more valid PSI-II is used to measure autonomy, some gender differences emerge; however, these gender differences have not always been replicated in other studies. In terms of the present study, it is important to note that none of the investigations of depressive symptoms and autonomy in the literature to date has examined the relation between gender, autonomy, and depressive symptoms in older adults. Thus, more investigation of the relation between gender and autonomy is needed.

Autonomy in older adults. Because the focus of the present study is on the possibility that autonomy might help to explain negative outcomes, such as suicidal ideation, in older adults, it is also important to examine literature which has investigated autonomy in late life. One early study (Mazure, Maciejewski, Jacobs, \& Bruce, 2002), examined the hypothesis that the interaction between autonomy (measured by the SAS) and the recent experience of an achievement stressor (loss of long-term residence) might predict depression in a group of older adults ( $M$ age 78 ; recruited from outpatient clinics and the community). Results from this study indicated that, although autonomy did not predict occurrence of depression $(O R=.45, p>.05)$, the interaction between high levels of autonomy and the experience of a negative achievement event (loss of long-term residence) did significantly predict onset of depression in late-life $(O R=5.80, p<.01)$. In another study (Voyer \& Cappeliez, 2002), it was hypothesized that the interaction between congruent life stressors and a cognitive schema related to autonomy (i.e. achievement; measured by the Dysfunctional Attitude Scale) would predict relapsed depression in older adults $(M$ age $=76)$ recruited from treatment programs for depression. Results indicated that neither the cognitive schema related to autonomy $(\beta=.03, S E=$ $.03, p>.05)$ nor the interaction between the cognitive schema and a congruent life stressor $(B=.10, S E=.06, p>.05)$ predicted relapse of depression. In a third study (Mazure \& Maciejewski, 2003a), the relation between the need for control sub factor of autonomy, as it is measured by the SAS, and the interaction between need for control and 
a congruent life stressor were examined in both younger $(M$ age $=40)$ and older depressed participants $(M$ age $=78)$. The results of this study indicated that individuals who are high in need for control are three times more likely to be depressed than individuals who are low in need for control; however, this relation was moderated by age, such that the relation between need for control and onset of depression was significantly less strong in older adults $\left[\chi^{2}(d f=1)=7.27, p<.01\right]$. Results also demonstrated that the interaction between need for control and achievement-related events was not as strong a predictor of depression in older adults $\left[\chi^{2}(d f=1)=7.47, p<.01\right]$. Finally, one study examined the relation between autonomy (measured by the PSI-II) and the possibility that the interaction between autonomy and negative life events would predict levels of depression 6 months after autonomy and the experience of life-events were assessed (Morse \& Robins, 2005). Participants $(N=55)$ in this study were older adults $(M$ age $=$ 68.09) followed at a mental health clinic. The results of this study indicated that the interaction between autonomy and congruent life stressors (which were not specified in the study) at Time 1 predicted level of depression at Time $2(\beta=.28, p<.05)$.

Overall, it appears that research has supported the hypothesis that older adults who are high in autonomy might become depressed after experiencing a congruent life stressor; however, it is possible that the relation may be smaller in magnitude than the relation between these three variables in younger adults. Two important criticisms of this literature should be noted, however. First, most of the studies reviewed utilized the SAS, which may not be as valid as the PSI-II (see above). Second, every investigation that examined the congruency hypothesis in older adults focused on negative life events that were not health related. This approach to the congruency hypothesis may be problematic, because it seems likely that stressors related to health status and functional impairment, more than any other type of stressors, are very likely to result in the types of problems in the use of control strategies that would predict problems in late life. It seems possible that independence-related events (such as functional impairment), rather than achievementrelated events, might be more distressing to older adults who are high in autonomy. All in all, previous research examining the possibility that high levels of autonomy in older adults predicts negative outcomes has not corresponded to theories of how problems in older adulthood might occur.

Autonomy, depression, and physical illness. The focus of the present study is on examining the possibility that a subset of functionally impaired older adults might develop suicidality due to high levels of a specific cognitive vulnerability (i.e. autonomy). Given this goal, it is important to examine the possibility that older adults who are high in autonomy might develop depression (which is one of the most important risk factors for suicidal behavior) after experiencing some sort of health-related loss. Most of the literature examining the congruency hypothesis (or the notion that individuals high in autonomy are likely to be more depressed when they experience an autonomyrelated stressor) have not examined health-related stressors; however, two studies have examined the relations among autonomy, physical illness, and depression. In the first study (Nordahl \& Stiles, 2007), three groups of middle-aged ( $M$ age ranged from 37.847.3) participants were compared in terms of level of autonomy (as it is measured by the SAS) and depression. One group had fibromyalgia (this group was recruited from a support group, $N=44$ ), one group had a diagnosis of Major Depressive Disorder (this 
group was recruited from an outpatient clinic, $N=41$ ), and the third group was a control group (this group was recruited from the community, $N=41$ ). The results of this study demonstrated no significant differences in level of autonomy between patients with fibromyalgia $(M=65.4, S D=16.5)$, patients with depression $(M=62.7 S D=16.3)$, and controls $(M=66.8, S D=13.6)$.

In the second study examining the relations among autonomy, illness, and depression (Stafford, Jackson, \& Berk, 2009), a group of 528 patients was followed longitudinally for 9 months after experiencing a surgery related to coronary artery disease (aged 38-91). At 3 months post-surgery, participants were administered the PSI-II and a measure of depression. They were administered the measure of depression again at 9 months postsurgery. Results indicated, first of all, that baseline level of autonomy was a significant predictor of depression at both Time $1\left(\beta=.46, p<.001, R^{2}=.12\right)$ and at Time $2(\beta=$ $\left..38, p<.001, R^{2}=.10\right)$. In addition to examining overall scores of autonomy, the authors also investigated the relation between the three subscales of the Autonomy scale of the PSI-II (i.e. need for control, defensive separation from others, and perfectionism). The results indicated that baseline level of perfectionism was the strongest predictor of depression at both Time $1\left(\beta=.36, p<.001, R^{2}=.05\right)$ and Time $2\left(\beta=.35, p<.001, R^{2}=\right.$ $.05)$.

All in all, the results of studies examining the relation between autonomy, physical illness, and depression have been mixed. The first study reviewed here did not find an association between autonomy, physical illness, or depression (Nordahl \& Stiles, 2007); however, it is important to point out several criticisms of this study. First, this study used the SAS to measure autonomy and some data suggest that the SAS is not a valid measure of this construct (Robins et al., 1994). Second, in this study, the presence of fibromyalgia was studied generally; however, both the congruency hypothesis and the model of dysfunction in late life presented in the MTLSD hypothesize that an individual might become particularly distressed very soon after encountering a particular stressor (Coyne \& Whiffen, 1995; Heckhausen \& Schulz, 2010). In this study, the temporal aspect of these hypotheses was not taken into account, which is problematic because most evidence suggests that individuals are more likely to be at risk for negative outcomes right after encountering a stressor (Coyne \& Whiffen). The other study reviewed here used a more valid measure of autonomy (i.e. the PSI-II) and a longitudinal design, which accounted for the temporal nature of the congruency hypothesis. The results of this more methodologically sound study supported the notion that certain people with long-standing vulnerabilities are at increased risk for negative outcomes after encountering a stressor that is congruent with their particular vulnerability.

Autonomy and suicidal behavior. In the present study, the negative outcome of interest is suicidal behavior. Given this interest, it is important to examine the relation between autonomy and suicidal behavior. No studies found during this literature review directly assessed the relation between autonomy and suicidal ideation; however, two studies examined the relation between autonomy and the different items of the Beck Depression Inventory (BDI; Beck, Ward, \& Mendelson, 1961), which includes one item assessing suicidal ideation. In the first study, over 2,067 adults ( $M$ age not reported) 
being treated for depression in an outpatient clinic were administered the SAS and the BDI (Clark et al., 1997). In this study, the suicidal ideation item on the BDI was not significantly correlated with autonomy ( $r$ was not reported). In the second study (Robins et al., 1997), 103 ( $M$ age $=39.8$ ) adults being treated for depression in an outpatient clinic were administered the BDI and the PSI-II. In this study, the suicidal ideation item of the BDI was significantly correlated with autonomy $(r=.52, p<.01)$.

In addition to these two quantitative studies examining suicidal ideation and autonomy, several qualitative studies have demonstrated that suicidal behavior might be related to a high need for autonomy in older adults. One recent study examined desire for death among the terminally ill (Wilson et al.). This group of researchers assessed 379 terminally ill cancer patients about their attitudes toward and desire for either physicianassisted suicide or euthanasia using a semi-structured interview. Most of the participants in this study reported that they had never desired either physician-assisted suicide or euthanasia, but, of those individuals who did desire death, nearly all of them reported that one of the major reasons they wanted a hastened death was because of a loss of autonomy (Wilson et al.). In a somewhat similar study, Filiberti and colleagues (2001) conducted a descriptive analysis of five cases of individuals who committed suicide while receiving palliative care for terminal cancer. Among a whole host of variables examined, one of the few variables that was present in every case was fear associated with loss of autonomy. In another descriptive study of deaths by suicide in individuals with illnesses, Rowe, Bruce, and Conwell (2006) conducted a descriptive psychological autopsy comparing 14 older adults who died by suicide while receiving home health care with 4 case controls who died of other causes. Of the 14 patients who died by suicide, eight had significant concerns about losing autonomy according to an intimate proxy. On the other hand, none of the control participants were reported to have fears associated with autonomy.

All in all, there is some evidence to suggest a possible association between autonomy and suicidal ideation; however, a great deal more research needs to be done. The two quantitative studies examining these variables did not directly assess the relation between suicidal ideation and autonomy and did not use a measure of suicidal ideation that has been shown to be reliable and valid. Similarly, qualitative studies in this area are of interest but it is also important to investigate this relation quantitatively.

A preliminary study. Because there have not been many studies examining the relation between autonomy and suicidal ideation, prior to conducting the current study, a preliminary study (O'Riley et al., 2008) was conducted. First of all, this study examined whether autonomy and/or the sub factors of autonomy, as they are measured on the PSIII, predict suicidal ideation in younger adults. Second, the possibility that autonomy might mediate the relation between gender and suicidal ideation in this sample was also assessed. In this study, 636 university students (97\% of whom were aged 18-24) were administered the PSI-II and the Suicidal Behaviors Questionnaire (SBQ-14; Linehan, 1981) as a measure of suicidal ideation. Results indicated that two of the three sub factors of autonomy were significant predictors of suicidal ideation in this sample. Specifically, it was found that both defensive separation $(B=.04, S E=.01, p<.01)$ and perfectionism $(B=.04, S E=.01, p<.01)$ predicted suicidality. In terms of the hypothesized mediation 
model, results, based on a bootstrapping model, indicated that autonomy partially explained the relation between gender and suicidal ideation in younger adults $(95 \% \mathrm{CI}=$ .60 to .49 ). The results of this preliminary study indicate that, for younger adults, some aspects of autonomy predict suicidal ideation, and autonomy appears to partially mediate the relation between gender and suicidality in younger adults.

\section{Research Questions, Hypotheses, and Exploratory Research Question}

Based on a preliminary study and research examining depression and depressive symptoms in both younger and older adults, there is some evidence suggesting that autonomy, as a long-standing vulnerability risk factor, might help to explain why a certain subset of older adults develops poor outcomes and, in particular, a high level of suicidal behavior, in response to stressors common in late life. As a preliminary examination of this model, the present study set out to examine the possibility, first of all, that autonomy predicts suicidal ideation in older adults. Because evidence suggests that only certain sub factors of autonomy are related to depression and depressive symptoms in older adults (e.g. see Mazure \& Maciejewski, 2003) and suicidal ideation in younger adults (O'Riley et al., 2008), the sub factors of the PSI-II autonomy scale (i.e. need for control, perfectionism, and defensive separation) were also investigated as predictors of suicidal ideation in older adults. If only certain sub factors were found to predict suicidal ideation in the present study, those sub factors were utilized in analyses instead of the total score of Autonomy.

In addition to this primary research question, several exploratory hypotheses were also examined. Another goal of the present study was to examine whether the relation between high levels of autonomy and suicidal ideation in older adults is stronger for individuals with more functional impairment. According to the MTLSD, functional impairment is one of the most difficult stressors with which older adults must cope, because this particular stressor has severe implications for one's ability to effectively engage in primary control strategies (Heckhausen et al., 2010). Thus, it seems reasonable to suggest that individuals with high levels of autonomy would be particularly likely to develop poor mental health outcomes in the face of high levels of functional impairment. A third goal of the present study was to examine the possibility that the relation between autonomy and suicidal ideation in late-life was partially mediated by willingness to seek help. This research question was based on Heckhausen and colleague's assertion that, as one ages, one must utilize more compensatory primary control strategies (e.g. help seeking) to compensate for the fact that one is no longer able to use direct primary control strategies. Given this assertion, it seems reasonable to suggest that one way in which cognitive vulnerabilities, such as autonomy, result in poor outcomes in the face of common stressors in late life is that these vulnerabilities may make it more difficult for individuals to utilize compensatory primary control strategies. A fourth goal of the present study was to examine the possibility that autonomy partially mediated the relation between gender and suicidal ideation. As was noted earlier, preliminary evidence suggests that autonomy partially mediates the relation between gender and suicidal ideation in younger adults (O'Riley et al., 2008). The present study attempted to replicate this finding in older adults. Because autonomy and depression and depressive symptoms 
have been found to be correlated in some studies, a final goal of the present study was to examine whether autonomy would predict suicidal ideation in older adults even when controlling for level of depressive symptoms. Given these goals, the following research questions and hypotheses were investigated in the present study:

\begin{tabular}{|c|c|c|}
\hline \multicolumn{3}{|r|}{ Research Question and Hypothesis } \\
\hline \multirow[t]{2}{*}{1.} & \multicolumn{2}{|c|}{ Does autonomy predict suicidal ideation in older adults? } \\
\hline & $\mathrm{H}_{1}$. & $\begin{array}{l}\text { Autonomy will be a significant positive predictor of suicidal ideation in older } \\
\text { adults, and the sub factors of autonomy (need for control, perfectionism, and } \\
\text { defensive separation) will differentially predict suicidal ideation in older } \\
\text { adults. If one or more sub factors of autonomy more strongly predicts suicidal } \\
\text { ideation, it may be used instead of the total score of autonomy for all } \\
\text { subsequent measures. }\end{array}$ \\
\hline \multicolumn{3}{|r|}{ Exploratory Research Questions and Hypotheses } \\
\hline \multirow[t]{2}{*}{1.} & \multicolumn{2}{|r|}{$\begin{array}{l}\text { Does level of functional impairment moderate the relation between autonomy (or } \\
\text { certain sub factors of autonomy) and suicidal ideation in older adults? }\end{array}$} \\
\hline & $\mathrm{H}_{2}$. & $\begin{array}{l}\text { Autonomy (or certain sub factors of autonomy) will be a stronger predictor of } \\
\text { suicidal ideation in older adults with higher levels of functional impairment. } \\
\text { If a significant moderation effect is found, level of functional impairment will } \\
\text { be included in model for Hypothesis } 4 \text {. }\end{array}$ \\
\hline \multirow[t]{2}{*}{2.} & \multicolumn{2}{|r|}{$\begin{array}{l}\text { Does willingness to seek help mediate the relation between autonomy (or certain sub } \\
\text { factors of autonomy) and suicidal ideation in older adults? }\end{array}$} \\
\hline & $\mathrm{H}_{3}$. & $\begin{array}{l}\text { Low willingness to seek help will partially mediate the relation between } \\
\text { autonomy (or certain sub factors of autonomy) and suicidal ideation in older } \\
\text { adults. }\end{array}$ \\
\hline \multirow[t]{2}{*}{3.} & \multicolumn{2}{|r|}{$\begin{array}{l}\text { Does autonomy (or certain sub factors of autonomy) mediate the relation between } \\
\text { gender and suicidal ideation? }\end{array}$} \\
\hline & $\mathrm{H}_{4}$. & $\begin{array}{l}\text { Autonomy (or certain sub factors of autonomy) will partially mediate the } \\
\text { relation between suicidal ideation and gender. }\end{array}$ \\
\hline \multirow[t]{2}{*}{4.} & \multicolumn{2}{|r|}{$\begin{array}{l}\text { Does autonomy (or certain sub factors of autonomy) predict suicidal ideation in older } \\
\text { adults even when controlling for level of depressive symptoms? }\end{array}$} \\
\hline & $\mathrm{H}_{5}$ & $\begin{array}{l}\text { Autonomy (or certain sub factors of autonomy) will be a significant positive } \\
\text { predictor of suicidal ideation in older adults even when controlling for level } \\
\text { of depressive symptoms. }\end{array}$ \\
\hline
\end{tabular}




\section{CHAPTER II: METHOD}

\section{Participants}

The data utilized in the present study were part of a larger data collection of variables related to suicidality in younger and older adults. The older adults who participated in this study were recruited via a commercially purchased mailing list with names and addresses of older adults in West Virginia, Pennsylvania, New Jersey, and Ohio. The participants were contacted by mail and asked to complete a written version of the survey used in this study. All together, 2,500 surveys were mailed and 88 were returned. For compensation, the participants were given the opportunity to win one of two raffle tickets for two $\$ 50$ prizes.

Table 1 presents the demographics of participants in the present study. The sample that was used for this study consisted of 88 adults aged 65 or older. Of these participants, most were aged 65-74 years old. Slightly more than half of the participants were men and most were European American. In terms of marital status, about half of the participants were married. The sample was nearly evenly divided in terms of rurality and education. Most of the sample had a yearly income of more than $\$ 25,000$ a year.

\section{Measures}

Center for Epidemiological Studies Depression Scale - Revised (CES-D-R). The CES-D-R (Eaton, Mutaner, Smith, Tien, \& Ybarra, 2004; please see Appendix 1) is a 20item self-report instrument that assesses several different types of depressive symptoms, including: somatic, depressive, affective, and interpersonal symptoms. When completing this questionnaire, participants are asked to specify how frequently they have experienced symptoms during the past week or so using a 5-point Likert-type scale, where a score of 0 indicates "not at all or less than one day", a score of 1 indicates "1-2 days," a score of 2 indicates "3-4 days," a score of 3 indicates "5-7 days," and a score of 4 indicates "nearly every day for 2 weeks." Total scores on this measure are derived by summing scores from each of the items, some of which were reversed scored. For the purposes of this study, two items (i.e. "I wished I were dead." And "I wanted to hurt myself") were not included in the analyses because, in this study, scores on the CES-D-R were used to test for suicidality, controlling for depressive symptoms (i.e. there would be criterion contamination). The CES-D-R has demonstrated moderately strong item-total correlations $(r=.31-.75)$. It has also been shown to be very strongly correlated with the original CES-D ( $r=.88-.93$ ). The original CES-D (Radloff, 1977) has demonstrated good internal consistency (Cronbach's alpha $=.85$ ) and moderately good test-retest reliability $(r=.5)$. Research has also demonstrated that the original CES-D has good reliability and validity for use with older adult samples (Gatz, Johansson, Pederson, Berg, \& Reynolds, 1993). In the present study, which utilized a 19 item version of the CES-D-R, internal consistency for the CESD-R was good (Cronbach's alpha $=.89$ ).

OARS Multidimensional Functional Assessment Questionnaire (OMFAQ). The OMFAQ (Fillenbaum \& Smyer, 1981) is a 20-item self-report measure (please see 
Appendix 2) that assesses activities of daily living (ADL) including physical activities of daily living (e.g. walking) and instrumental activities of daily living (e.g. managing money). Participants are asked to respond to this questionnaire based on a 3-point scale, where a score of 3 indicated they were able to perform a given activity without help, a score of 2 indicated they could perform the activity with help, and a score of 1 indicated they could not perform the activity at all. For the purposes of this study, scores were reversed and summed so that higher scores on this instrument indicated higher levels of impairment. Research has demonstrated the OMFAQ has good validity in that scores on this instrument are highly correlated with ratings of disability by physicians $($ tau $=.62-$ .83; Fillenbaum \& Smyer, 1981). Also, in a longitudinal study of Swedish twins, the total OMFAQ score demonstrated good internal consistency (Cronbach's alpha $=.89-.96$ ) across several measurement periods (Lichtenstein et al., 2002). In the present study, internal consistency for the OMFAQ was good (Cronbach's alpha $=.95)$.

The Personal Style Inventory - Revised (PSI-II). The Personal Style Inventory Revised (PSI-II; Robins et al., 1994) is a measure of sociotropy and autonomy, which can be conceptualized as excessive concern about relationships and excessive concern about achievement, respectively. Because the PSI and the PSI-II are very similar $(r=.90$; Robins et al.), psychometric studies using both versions of this instrument will be described. Robins and colleagues have demonstrated that the PSI and the PSI-II have very good reliability and validity. First, the authors have demonstrated good internal reliability (Cronbach's alpha between .84 and .90) for both of the scales of the PSI and the PSI-II in a sample of depressed patients, control subjects, and several different undergraduate samples (Robins et al.). Second, both versions of the PSI have demonstrated good construct validity based on factor analyses. For both versions, all of the items loaded on the correct factor (sociotropy or autonomy), and, in the final version of this instrument (the PSI-II), the item loadings were above .30 with the correct factor and.20 and below for the incorrect factor (Robins et al.). In addition, construct validity was demonstrated by the fact that the subscales of this measure were weakly, positively correlated with depressive symptoms, as measured by the Beck Depression Inventory (Beck et al., 1961; Sociotropy $r=.20$ and Autonomy $r=.27$ ), which would be expected for risk factors that increase vulnerability to depressive symptoms. Third, the PSI-II has demonstrated both convergent and divergent validity in a derivation and validation sample of undergraduates. Specifically, the subscales of the measure were significantly positively correlated with the scales of the SAS (Sociotropy $r=.10$ to .84 and Autonomy $r=.11$ to .50$)$, and only weakly correlated with each other $(r=.21)$. Finally, test-retest reliability over a period of 5 to 13 weeks was good (Sociotropy $r=.80$ and Autonomy $r=$ .70), which indicates that this instrument is reliably measuring fairly stable variables.

For the purposes of the present study, only the Autonomy subscales of the PSI-II were utilized (please see Appendix 3 for the items of the Autonomy subscale of the PSI-II) as a measure of autonomy. The Autonomy subscale of the PSI-II is a 24-item scale that consists of three factors of Autonomy (Robins et al., 1994): excessive perfectionism (e.g. "It bothers me when I feel that I am only average and ordinary"), need for control (e.g. "I am easily bothered by other people making demands on me"), and defensive separation (e.g. "I tend to keep other people at a distance"). Respondents are asked to rate each item 
based on a 6-point Likert-type scale (where 1 is strongly disagree and 6 is strongly agree). Scores on this scale range from 24 to 144, with higher scores indicating higher levels of autonomy. In the proposed study, participants' scores were summed for this instrument and analyzed as a continuous variable. In the present study, internal consistency for the PSI-II Autonomy subscale was good (Cronbach's alpha $=.90$ ).

The Willingness to Seek Help Questionnaire (WSH). The Willingness to Seek Help questionnaire (WSH; Cohen, 1999) is a 25-item self-report measure (please see Appendix 4) designed to assess three domains of help-seeking, including: the willingness to admit a need for help, whether or not an individual is prepared for self-disclosure, and the willingness to give up control. The measure also includes five social desirability items designed to assess validity of responses. For this scale, respondents are asked to rate the degree to which they agree with a series of statements based on a 4-point Likert-type scale (where 0 is do not identify at all and 3 is identify completely), and total scores are derived by summing scores from each item, some of which are reversed scored. Higher scores on this instrument indicate more resistance to help seeking. The WSH has been shown to have good internal consistency (Cronbach's alpha $=.85$; Cohen). The core 20 items of the scale have also been shown to have discriminant validity with respect to the social desirability scale included in the measure $(r=.02)$ and some convergent validity with respect to questions that assess actual help-seeking behaviors $(r=.34)$. In the present study, internal consistency for the WSH was good (Cronbach's alpha $=.84$ ).

The Suicidal Behaviors Questionnaire (SBQ- 14). The SBQ-14 (Linehan, 1981) is a 14-item self-report measure (please see Appendix 5) designed to assess past suicidal ideation, future suicidal ideation, past suicide threats, future suicide attempts, and likelihood of dying in a future suicide attempt. For ethical reasons, one of the items of this measure, which asked about current plans for suicide, was not included in this study. A total score for this measure was derived by summing all of the items, with higher scores indicating higher levels of suicidal ideation. The SBQ-14 has demonstrated high internal reliability ( $r=.73-.92$; Addis \& Linehan, 1989). In terms of construct validity, a principal components factor analysis demonstrated that the SBQ-14 is unidimensional. In terms of convergent validity, the total score of the SBQ-14 is moderately, positively, correlated ( $r=.55-.62$; Linehan \& Addis, 1990) with the Beck Scale for Suicidal Ideation (Beck \& Steer, 1991), the Beck Depression Inventory (Beck et al., 1961), and the Beck Hopelessness Scale (Beck \& Steer, 1988). Finally, the short-form of the SBQ (the SBQR) has demonstrated excellent AUC scores (.96), which indicates that it correctly classifies those with and without risk (Osman et al., 2001). In the present study, internal consistency for the SBQ was good (Cronbach's alpha $=.80$ ).

\section{Procedure}

This study was approved by the Institutional Review Board of West Virginia University (IRB \# H-20432). Participants for this study were recruited via a commercially purchased mailing list with names and addresses of older adults in West Virginia, Pennsylvania, New Jersey, and Ohio. The participants were contacted by mail with a packet. The packet included two copies of an informed consent form, a raffle ticket, a list of mental health providers (which the participant was encouraged to contact in the event that he or she was 
experiencing significant psychological distress), and a paper and pencil survey consisting of several different measures. Participants were asked to complete one copy of the informed consent and the survey, which included the instruments used in this study. They were provided with a toll-free telephone number they could call in the event they had questions about the survey. Participants were then asked to return the survey and the completed copy of the informed consent using a stamped and addressed envelope provided to them. Each person was also asked to return the raffle ticket with their name and address on it. Raffle tickets were immediately removed from returned data packets (which were kept in a locked cabinet) to ensure the confidentiality of the data. After data collection for this study was complete, a drawing was held using the raffle tickets. The two participants chosen from this drawing received $\$ 50$ each.

\section{CHAPTER III: RESULTS}

All analyses were conducted using SPSS statistical software. Table 2 presents descriptive statistics for all of the variables of interest in this study. Table 3 presents Pearson correlations between the variables of interest.

\section{Missing Data Analyses}

Missing data was a significant problem in the present study. All of the variables used in these analyses had missing data (please see Table 4 for the percentage of missing data for each variable of interest). In order to determine if these data were systematically missing, several analyses were conducted. First of all, the data set was split according to whether individuals had any missing data. Next, independent samples $t$-tests were conducted to determine whether the means for each variable of interest (i.e. total score on the WSH, total score on the PSI-Autonomy subscale, total score on the CES-D-R, total score on the SBQ-14, and total score on the OMFAQ) varied according to whether individual participants had any missing data on any variables. Table 5 provides the results of these analyses. Overall, the mean scores for the variables of interest for individuals with missing data did not significantly vary from the mean scores for the variables of interest for individual without missing data. In addition to the independent samples $t$-tests conducted, Chi-Square Tests of Independence were conducted to determine whether participants with missing data significantly varied from participants without missing data in terms of demographic variables. Table 6 provides the results of these analyses. Overall, it appears that individuals with missing data did not significantly differ from participants without missing data in terms of age, ethnicity, rurality, or income (please see Table 6); however, The Chi-Square Tests of Independence for education was approaching significance suggesting that individuals with lower levels of education may have had higher percentages of missing data than individuals with higher levels of education.

Given the results of the missing data analyses, it appears that the data in this study were MAR (missing at random; Tabachnick \& Fiddel, 2007, pp. 62-72). Researchers have suggested that the most appropriate way to handle MAR data is to use multiple imputation to estimate missing values (Tabachnick \& Fiddel; Schafer, 1999). Multiple imputation is an ideal way to handle some types of missing data because it allows one to 
factor true variability into derived scores. Given this advantage, the Multiple Imputation module in SPSS was utilized to deal with the missing data in this study. Multiple imputation is a method of generating multiple simulated values for each incomplete variable (Schafer). In the present study, five different simulated data sets were created. After these datasets were derived, they were then iteratively analyzed and combined into pooled statistics. Interestingly, in the present study, the pattern of pooled results combined across the five data sets created through multiple imputation did not significantly differ from the pattern of results derived from the original dataset (with missing data). Given the fact that using multiple imputation did not change the pattern of results derived in the present study, for the sake of simplicity, only the results from the original dataset are presented below. In this dataset, missing data were deleted listwise.

\section{Analyses for Hypothesis 1}

Assessing assumptions. Before conducting the analyses for Hypothesis 1, preliminary analyses were conducted to determine whether the assumptions of a simple linear regression were met (Osborne, \& Waters, 2002). In terms of normality, a Kolmogorov-Smirnov test indicated that scores on the Autonomy subscale of the PSI (the independent variable in this analysis) were normally distributed, KS test $=.09(47), p=$ .20 . The data were not significantly skewed (Skewness $=.55, S E=.35$ ) and level of kurtosis was within normal limits (Kurtosis $=.02, S E=.68$ ). Because the sample used in this study was a community-sample, it was expected that scores on the SBQ-14 (the dependent variable in this analysis) would be positively skewed. Although a Kolmogorov-Smirnov test indicated that scores on the SBQ-14 were not normally distributed $[\mathrm{KS}$ test $=.24(47), p<.01]$, the data were not significantly skewed (Skewness $=.96, S E=.35$ ) and level of kurtosis was within normal limits (Kurtosis $=-.31, S E=$ .68). Given these findings, the scores for the SBQ-14 were not transformed for these analyses. In addition to tests of normality, plots of the standardized residuals and standardized predicted residuals were also examined. These plots demonstrated that the assumptions of homoscedasticity and linearity were met for these analyses. Next, to assess multicollinearity, Pearson correlations were conducted (see Table 3). Results demonstrated that the correlation between the total score of the Autonomy subscale of the PSI-II and the total score on the SBQ-14 was not high enough to raise concern $(r=.01, p$ $>$.05); thus, multicollinearity was not a concern for this analysis. Correlations for the total score of the SBQ-14 and the three subscales of the Autonomy subscale of the PSI-II are presented in Table 3. Results indicated that neither the Defensive Separation Subscale nor the Perfectionism subscale of the PSI-II was significantly correlated with suicidal ideation. Thus, multicollinearity was not a concern in terms of these variables. The Need for Control sub-scale of the PSI-II was significantly correlated with the total score of the SBQ-14 $(r=.25, p<.01)$; however, it was not highly correlated, so multicollinearity was not a concern for these variables either.

Analysis 1. A simple linear regression analysis was conducted in order to determine whether autonomy (a continuous variable) significantly predicted suicidal ideation among the older adults in this sample. Significance for the regression coefficient was set at $p<.05$. Basic descriptive statistics and regression coefficients are shown in 
Table 7. The Autonomy subscale of the PSI-II was not a significant predictor of suicidal ideation in the regression model. The model accounted for less than $.01 \%$ of the variance in suicidal ideation, $F(1,67)=.003, p>.05$. A $95 \%$ confidence interval for $R^{2}$ extends from -.004 to .005 .

Additional analyses for hypothesis 1. Because past research has demonstrated that the different sub factors of the Autonomy subscale of the PSI-II (i.e. Need for Control, Defensive Separation, and Perfectionism) might differentially predict depressive symptoms in older adults (Mazure \& Maciejewski, 2003; Mazure et al., 2002), a multiple linear regression was used to develop a model for predicting suicidal ideation from the three sub factors of the Autonomy subscale of the PSI-II (all three sub factors are continuous variables). An examination of the residual plots for these analyses demonstrated that the assumptions of homoscedasticity and linearity were met. Basic descriptive statistics and regression coefficients for this model are shown in Table 8. Of the three sub factors of the Autonomy subscale of the PSI-II, only Need for Control was significantly correlated with suicidal ideation. Need for Control was also the only predictor that had a significant partial effect in the full model. The three predictor model was able to account for $8 \%$ of the variance in suicidal ideation, $F(3,69)=2.02, p=.12$. A $95 \%$ confidence interval for $R^{2}$ extends from -.03 to .19. Because Need for Control was the only significant predictor in this model, only this subscale was utilized in subsequent analyses that involved autonomy.

\section{Analysis for Hypothesis 2}

Assessing assumptions. Before conducting the analysis for Hypothesis 2, preliminary analyses were conducted to determine whether the assumptions of a multiple linear regression were met. As was mentioned previously, preliminary analyses demonstrated that neither the Autonomy subscale of the PSI-II nor the SBQ-14 had problems with skew or kurtosis. However, preliminary analyses demonstrated that scores on the OMFAQ were not normally distributed, KS test $=.37(47), p<.01$. Because this variable had significant skew (Skewness $=-5.77, S E=.35$ ) and kurtosis (Kurtosis = $36.43, S E=.68$ ), an inverse transformation was performed. Although a KolmogorovSmirnov test indicated that scores on the transformed OMFAQ were not normally distributed $[\mathrm{KS}$ test $=.39(67), p<.01]$, the data were not significantly skewed (Skewness $=-.76, S E=.30)$ and level of kurtosis was within normal limits (Kurtosis $=-1.12, S E=$ .59). Next, to assess multicollinearity, Pearson correlations were conducted (see Table 3). As was indicated above, the Need for Control sub factor of the PSI-II was significantly correlated with the total score of the SBQ-14 $(r=.25, p<.01)$; however, it was not highly correlated, so multicollinearity was not a concern for this variable. The OMFAQ total score was not significantly correlated with the total score of the SBQ-14 $(r=.21, p$ $>.05)$; thus, multicollinearity was not a concern for this variable either.

Analysis. In order to test whether need for control was a stronger predictor of suicidal ideation in older adults with higher levels of functional impairment, a multiple linear regression was conducted in which need for control (a continuous variable), measured by the PSI-II, functional impairment (also a continuous variable) as it is measured by the OMFAQ, and the interaction between need for control and functional 
impairment were entered as predictors of suicidal ideation as it is measured on the SBQ14. Prior to conducting this multiple linear regression, the variables in the reaction term (need for control and functional impairment) were centered. Significance for the regression coefficients was set at $p<.05$. Basic descriptive statistics and regression coefficients for this model are shown in Table 9. In this model, only the main effect of need for control significantly predicted suicidal ideation. The main effect of functional impairment and the interaction between need for control and functional impairment were not significant predictors of suicidal ideation in this model. Overall, the model was able to account for $9 \%$ of the variance in suicidal ideation, $F(3,66)=2.15, p=.10$. A $95 \%$ confidence interval for $R^{2}$ extends from -.03 to .21 .

\section{Analysis for Hypothesis 3}

To test the hypothesis that willingness to seek help may partially mediate the relation between autonomy and suicidal ideation in older adults (please see Figure 4 for a visual representation of this model), the nonparametric bootstrap framework was utilized. Researchers have traditionally used Baron and Kenny's (1986) regression model to test meditational relationships; however, several criticisms of this model have been raised. Specifically, it has been suggested that the Baron and Kenny model has low power, is vulnerable to Type II error, and, perhaps most importantly, it does not address whether the indirect effect in a mediation model is significantly different from zero and in the expected direction (Mackinnon, Lockwood, Hoffman, West, \& Sheets, 2002). Bootstrapping addresses these concerns and has the added benefit of not being based on large-sample theory (Preacher \& Hayes, 2004; Shrout \& Bolger, 2002). Given these benefits, bootstrapping is ideal for small samples. Bootstrapping involves repeatedly, randomly sampling observations from data, sampling with replacement, and then deriving the indirect effect in a meditational model in each sample (Preacher \& Hayes). This method allows the distribution of the indirect effect to be examined quantitatively (Shrout $\&$ Bolger). The elements of the vector for all of the estimates made are sorted from low to high and "cut-off" scores are determined (based on how many samples are requested and what level of confidence is being examined; Preacher \& Hayes). If the confidence interval does not include zero, it is concluded that the indirect effect is significant. For the purposes of this analysis, the dependent variable for the bootstrap framework was suicidal ideation, as it is measured by the SBQ-14. The independent variable was need for control, as it is measured by the PSI-II, and the proposed mediating variable was willingness to seek help, as it is measured on the WSH. A confidence interval of $95 \%$ was examined for significance testing.

Table 10 presents the results of the mediation model. In this analysis, results based on 5000 bootstrapped samples (this is the number of samples most often used for mediation models; Preacher \& Hayes, 2004) indicated that the total effect of need for control on suicidal ideation was not significant. The direct effect of willingness to seek help on need for control was significant, but the direct effect of willingness to seek help on suicidal ideation was not significant. Willingness to seek help did not mediate the relation between need for control and suicidal ideation in this model (IE lower 95\% CI $=-.07$, upper $95 \% \mathrm{CI}=.11$ ). Because zero is in the $95 \%$ confidence interval, the indirect effect 
does not significantly differ from zero (Point Estimate $=.02, S E=.04, p>.05$ ). Finally, an effect size was calculated based on Fairchild, MacKinnon, Taborga and Taylor's (2009) formula for calculating the proportion of variance in the dependent variable (suicidal ideation) accounted for by the indirect effect of the independent variable (need for control) on the dependent variable (suicidal ideation) through the proposed mediating variable (willingness to seek help). The results of this calculation indicated that the variance in suicidal ideation accounted for by the indirect effect was .008, which is a very small effect size.

\section{Analysis for Hypothesis 4}

Prior to conducting a test of this hypothesis, a simple linear regression analysis was conducted in order to determine whether gender significantly predicted suicidal ideation among the older adults in this sample. Table 11 presents basic descriptive statistics for this analysis. Because gender was a dichotomous variable in this analysis, it was dummycoded such that 0 indicated female gender and 1 indicated male gender Significance for the regression coefficient was set at $p<.05$. Gender was not a significant predictor of suicidal ideation in the regression model. The model accounted for less than $2 \%$ of the variance in suicidal ideation, $F(1,76)=1.50, p>.05$. Table 12 presents the regression coefficients and basic descriptives for this analysis. Because gender was not related to suicidal ideation in this sample, it was not appropriate to conduct the bootstrapping analysis to explore the possibility that need for control mediated the relation between gender and suicidal ideation.

\section{Analysis for Hypothesis 5}

Assessing assumptions. Before conducting the analysis for Hypothesis 5, preliminary analyses were conducted to determine whether the assumptions of a hierarchical multiple regression were met. As was mentioned previously, preliminary analyses demonstrated that neither the Autonomy subscale of the PSI-II nor the SBQ-14 had problems with skew or kurtosis. However, preliminary analyses demonstrated that scores on the CES-D-R were not normally distributed, KS test $=.22(47), p<.01$. Because this variable had significant skew (Skewness $=2.34, S E=.35$ ) and kurtosis (Kurtosis $=6.24, S E=.68$ ), a square root transformation was performed. After this transformation, a Kolmogorov-Smirnov test indicated that scores on the transformed CES-D-R were normally distributed [KS test $=.09(67), p=.20]$, the data were also not significantly skewed (Skewness $=.55, S E=.30$ ) and level of kurtosis was within normal limits (Kurtosis $=.39, S E=.59$ ). In addition to tests of normality, plots of the standardized residuals and standardized predicted residuals were also examined. This plot demonstrated that the assumptions of homoscedasticity and linearity were met for this analysis. Next, to assess multicollinearity, Pearson correlations were conducted (please see Table 3). As was indicated above, the Need for Control sub-scale of the PSI-II was significantly correlated with the total score of the SBQ-14 $(r=.25, p<.01)$; however, it was not highly correlated, so multicollinearity was not a concern for this variable. The CES-D-R total score was significantly correlated with the total score of the SBQ-14 ( $r=$ $.18, p<.05)$; however, again, it was not highly correlated, so multicollinearity was not a 
concern for this variable. As was indicated above, overall, both the PSI-II Autonomy subscale and the SBQ-14 demonstrated good reliability.

Analysis. In order to test whether need for control predicted suicidal ideation when controlling for depressive symptoms, a hierarchical regression was conducted. On the first step, depressive symptoms, as they are measured on the CES-D-R, was entered into the model. On the second step both depressive symptoms and need for control were entered into the model simultaneously. Significance for the regression coefficients was set at $p<.05$. Table 13 presents the results of the hierarchical multiple regression analysis. On the first step, depressive symptoms were not significantly correlated with suicidal ideation and it was not a significant predictor of suicidal ideation in the regression model. Depressive symptoms accounted for more than $3 \%$ of the variance in suicidal ideation, $F(1,67)=2.15, p=.15$. When depressive symptoms controlled for, need for control was no longer a significant predictor of suicidal ideation in older adults. When need for control was added to the overall model, the increase in $R^{2}$ was not significant, $F(1,60)=2.554, p=.12$. The full model was not significant, $F(2,60)=2.38$, $p=.10$. Overall, depressive symptoms and need for control accounted for $7 \%$ of the variance in suicidal ideation in older adults.

\section{CHAPTER IV: DISCUSSION}

\section{Summary of Results}

All in all, only Hypothesis 1, which predicted that the sub factors of autonomy would differentially predict suicidal ideation, was partially supported in this study. Results indicated, first of all, that the total score of Autonomy on the PSI-II did not significantly predict suicidal ideation in this sample. When the three sub factors of autonomy were examined (need for control, defensive separation, and perfectionism), only need for control was a significant, positive predictor of suicidal ideation in the older adults in this study. Because only need for control significantly predicted suicidal ideation in this study, all subsequent analyses involving autonomy utilized only the Need for Control sub factor of the PSI-II. In terms of Hypothesis 2, which predicted that functional impairment would moderate the relation between need for control and autonomy, level of functional impairment did not moderate the relation between need for control and suicidal ideation in this study. In terms of Hypothesis 3, which predicted that willingness to seek help would mediate the relation between need for control and autonomy in this sample, willingness to seek help did not mediate the relation between autonomy and suicidal ideation in this study. Similarly, need for control did not mediate the relation between gender and suicidal ideation in the older adults in this study. Finally, when levels of depressive symptoms were controlled for, need for control was no longer a significant predictor of suicidal ideation in this study.

\section{Significance}

The results of the present study are very interesting for several reasons. First, the results of this study suggest that the relation between autonomy and suicidal ideation in older 
adults is very different from the relation between autonomy and suicidal ideation in younger adults. As was noted above, previous studies have demonstrated that the Defensive Separation and Perfectionism sub factors (and not the Need for Control subscale) of PSI-II have been shown to be significant predictors of suicidal ideation in college students (O'Riley et al., 2008). The present study demonstrated that a different component of autonomy is predictive of suicidal ideation in older adults. Similarly, previous work has shown that autonomy mediates the relation between gender and suicidal ideation in younger adults (O'Riley et al., 2008). Interestingly, the present study suggests that this relation may not hold true in older adulthood. The differences found between younger and older adults in these two studies may reflect either true age differences in the relation between the sub factors of autonomy and suicidal ideation, or they may reflect possible cohort differences. More investigation of these variables using more stringent designs (i.e. longitudinal designs) is necessary in order to determine whether the effects seen in these two studies are based on age or cohort effects.

The results of the present study are congruent with a series of studies conducted by Mazure and colleagues (Mazure et al., 2001; Mazure et al., 2002). As was noted above, Mazure and colleagues (2001) demonstrated that only the Need for Control sub factor of Autonomy (as measured on the SAS) predicted depression in older adults. The results of the present study suggest that need for control is also a better predictor of suicidal ideation in older adults than either defensive separation or perfectionism. Similarly, although Mazure and colleagues (2002) demonstrated that the interplay between cognitive vulnerability and specific life stressors predicts depression or depressive symptoms in older adults, their work suggests that the predictive value of the interaction between need for control and achievement related stressors is smaller in older adults than in younger adults. The present study suggests the interaction between need for control and a congruent life stressor (functional impairment) does not significantly predict suicidal ideation in older adults.

Finally, the results of the current study provide some interesting information in terms of the Motivational Theory of Life-Span Development. In this study, only the Need for Control sub factor of the PSI-II predicted suicidal ideation in older adults. When the items of this scale are examined (please see Appendix 3), it seems that this scale best reflects the notion, put forth by Heckhausen (1997), that, in order to age successfully, one must demonstrate increased flexibility in goal adjustment. Need for control, as it is measured on the PSI-II, seems to reflect inflexibility. Interestingly, this finding is also in line with research that demonstrates that low openness to experience (another measure of inflexibility) might be related to suicidal behavior in older adults but not younger adults (Duberstein, 1996).

\section{Limitations}

Use of a mailed survey. The use of a mailed survey was a major limitation in this study for several reasons. First, the use of survey research, in general, has some major limitations. In general, the validity of self-report research may be questionable, because the extent to which individuals can accurately report on their own private experiences and 
overt behaviors is questionable (Whitley, 2002). In addition, evidence suggests that individuals are not always willing to self-disclose personal information on self-report questionnaires, even when anonymity is guaranteed (Whitley). This is particularly the case when individuals are asked to self-disclose about very personal information (such as depressive symptoms and/or suicidal ideation). Third, because the self-report surveys used in this study were sent as mailed questionnaires, it is unclear whether participants accurately understood the questions in this survey and the response format used (participants in this survey were given a toll-free number they could telephone to ask questions about the survey, but it is unclear if everyone who had questions utilized this service).

In addition to these general concerns about the self-report questionnaires used in this study, more specific concerns about mailed surveys should be noted. Research suggests that mailed surveys consistently have lower response rates than other sampling methods (Whitley, 2002), and older adults have lower response rates than other age groups (between 16-49\%; Kaldenberg, Koenig, \& Becker, 1994). This is problematic because it is likely that sampling bias occurs. That is, the type of individual who is willing to complete and return a survey may not be representative of the general population of interest (Whitley). This limitation is particularly problematic in the current study, because the response rate in this study was particularly low (3\%). It may be that the population of interest (i.e. individuals who are experiencing losses associated with aging) would be particularly unlikely to complete and return a self-report survey due to functional limitations and symptoms of depression. In addition, the sample that did complete this survey was more highly educated than the general population of older adults in the United States (according to U.S. Census Data, only 75.2\% of individuals over 65 years of age have higher than a high school education; United States Census, 2008). Again, this limitation suggests that the sample in this study may not be representative of the general population of interest. Finally, there is evidence that the use of mailed surveys results in more missing data than other sampling methods, especially when older adults are surveyed (Whitley; Kaldenberg et al.). In the present study, using multiple imputation did not change the results of the study, which suggests that missing data did not result in Type II error. Nevertheless, the use of a different sampling method (e.g. administering surveys in person) might have resulted in less missing data. Despite the limitations inherent in using a mailed survey, the results of the present study demonstrate preliminary evidence of a possible risk factor for suicidality in older adults.

Use of a community-based sample. Another major limitation of the present study was the use of a community-based sample. This limitation is indicative of criticisms about the literature examining autonomy more generally. Coyne and Whiffen (1995) have pointed out that studies examining autonomy may not be generalizable to the populations most of interest (that is, individuals with a diagnosis of Major Depressive Disorder or clinically significant symptoms of depression), because most studies examine autonomy in community-based samples. The use of a community-based sample suggests the results of the present study may not generalize to individuals who are experiencing significant levels of suicidality. Additionally, it is possible that the reason level of depressive symptoms did not significantly predict suicidal ideation in the present study might be that 
the number of participants in the present study with a level of depressive symptoms above the recommended cut-off score for the CESD-R (i.e. 16; Eaton et al., 2004) was very small $(N=6)$. The use of a clinical sample may have been a more appropriate way to examine the relation between need for control, suicidal ideation, and depressive symptoms in the current study, but, it is important to note, that this study represents a critical first step toward examining the possibility that a high need for control might result in negative outcomes in late life.

Use of suicidal ideation as an outcome measure. Another potential limitation of the present study is related to the use of suicidal ideation as an outcome measure. Traditionally suicidal behavior has been seen as operating on a continuum where suicidal ideation leads to suicide attempt(s), which ultimately might lead to death by suicide (Kessler, Borges, \& Walters, 1999; O’Carroll, Berman, Maris, Moscicki, Tanney, \& Silverman, 1996). Recent evidence suggests, however, that different suicidal behaviors may actually be orthogonal (Casey et al., 2008). On the one hand, a large percentage of individuals who die by suicide appear to have reported suicidal ideation prior to their deaths. For example, in a psychological autopsy study, Waern, Beskow, Runeson, and Skoog (1999) demonstrated that $11 \%$ of older adults who died by suicide reported suicidal ideation to a healthcare professional and $28 \%$ reported suicidal ideation to a family member. On the other hand, however, international studies have demonstrated that rates of suicidal ideation in the general population (8-15\%) are much higher than rates of death by suicide (less than .01\%; Casey et al., 2008). In addition, several studies have found that different risk factors might differentially predict suicidal ideation, suicide attempt, and death by suicide in late life (see e.g. Useda et al., 2007). Indeed, one study that directly examined the question of whether suicidal ideation is an appropriate "surrogate endpoint" (i.e. a laboratory measurement that can be used as a clinically meaningful endpoint) for death by suicide in older adults determined that, at the present time, there is only moderate evidence that this is a valid methodological practice (Links, Heisel, \& Quastel, 2005). Links and colleagues suggest that one might increase the validity of suicidal ideation as an outcome measure by adding items assessing individuals' intent to die by suicide. The present study used the SBQ-14 as a measure of suicidal ideation, which includes several items that directly address level of intent (please see Appendix 4; Linehan, 1981). However, it should be noted that scores on the SBQ-14 in the present study were not highly correlated with variables that are usually correlated with suicidal behavior (such as depressive symptoms). This finding suggests that the results of the present study may not generalize to the population of most interest (i.e. individuals who are at highest risk for death by suicide). Although the results of this study cannot be directly generalized to death by suicide, the findings do suggest that need for control is related to suicidal ideation, which is a risk factor for death by suicide.

Use of a general measure of functional impairment in a community sample. A final limitation of the present study centers on the way functional impairment was measured in this study. In their critique of the literature examining autonomy, Coyne and Whiffen (1995) point out that Beck's congruency hypothesis (Beck et al., 1982) is, in essence, a temporal model. That is, in Beck's model an individual with a cognitive vulnerability to depression (in this case, high levels of autonomy) comes in contact with a 
life stressor that is congruent with this vulnerability and then develops depression (see Figure 4). Most of the research examining the congruency hypothesis (including the present study) does not take the temporal aspect of this model into account (Coyne \& Whiffen). Thus, in the current study a general measure of functional impairment was administered, but the study failed to assess when the participant's functional impairment occurred. Given this failure, even if functional impairment was found to moderate the relation between need for control and suicidal ideation in the present study, this finding would not have provided direct support for the congruency hypothesis (because there was no way of knowing the causal order of events given the methodology utilized in the present study).

In addition, the measure of functional impairment in this study was problematic because of the use of a community-based sample. The range of scores on the functional impairment measure used in this study (the OMFAQ) was fairly small (21-63), which indicates that most of the older adults in this sample did not have significant functional impairment. It is possible that functional impairment may have moderated the relation between need for control and suicidal ideation in this study if the sample collected had included more older adults with significant functional impairment.

\section{Future Directions}

Addressing limitations. Given the limitations in the present study, more research examining the relation between Beck's construct of autonomy and suicidal behavior in older adults is warranted. Future studies addressing limitations in the present study should focus on examining need for control and independence in clinical samples. Of particular interest would be examining rates of need for control in a sample of older adults who have made serious suicide attempts. A study in this clinical population would allow one to more readily conclude whether high levels of need for control put older adults at risk for suicide.

In addition to examining clinical populations, in order to examine whether Beck's congruency hypothesis (Beck et al., 1982) can be generalized to suicidal behavior in older adults, it would be useful to conduct a longitudinal study examining whether older adults with a high need for control and no functional impairment later go on to develop symptoms of depression and suicidal behavior after experiencing a stressor that threatens their independence and autonomy.

Examining the relation between need for control and the use of primary and secondary control strategies. The present study provides preliminary evidence that individuals with high levels of need for control might be at risk for negative outcomes (in this case, suicidal ideation). Given this outcome, further examinations of the relation between need for control and problems in late life seem warranted. In the present study, the use of one type of compensatory primary control strategy (i.e. help seeking) did not mediate the relation between need for control and suicidal ideation. However, future research might set out to examine the possibility that the relation between need for control and suicidal ideation is partially mediated by other aspects of the MTLSD. For 
example, perhaps the relation between need for control and suicidal ideation is mediated by a lack of utilization of secondary control strategies.

Intervention. The ultimate goal of most studies examining risk factors for suicidal behavior is to facilitate the development of interventions that might ameliorate risk for death by suicide. It is possible that the present study and other similar research could be utilized to help identify and create interventions specifically designed for older adults who are at increased risk for suicide due to difficulties coping with loss of independence and control. The present study suggests that a high need for control predicts suicidal ideation in community-dwelling older adults. This finding dovetails nicely with research that indicates that coping styles marked by avoidance and control strategies may be related to suicidal ideation in older adults (Cukrowicz, Ekblad, Vheavens, Rosenthal, \& Lynch, 2008). It also supports hypotheses based on models of normal aging, which suggest that, in order to cope with loss, one must increase secondary control strategies (Heckhausen et al., 2010). All in all, this line of research suggests points of intervention to help individuals who are not successfully coping with stressors associated with aging. For example, it may be possible to modify existing interventions designed to increase flexibility and to decrease avoidance and control strategies [e.g. Acceptance and Commitment Therapy (Hayes, Strosahl, \& Wilson, 2003) or Mindfulness-Based Cognitive Therapy for Depression (Segal, Williams, \& Teasdale)] to specifically address the risk factors identified by this line of research.

\section{Conclusion}

The present study provides useful information about a potential risk factor for suicidal behavior in older adults. It appears that a high need for control is associated with suicidal ideation in older adults. Interestingly, this finding is quite different from findings in a previous study of younger adults (which suggested that high levels of defensive separation and perfectionism, but not high levels of need for control were associated with suicidal ideation; O'Riley et al., 2008). The results of this study have interesting implications for the development of intervention and prevention programs for late life suicide and for the possibility of tailoring interventions to best meet the needs of older adults who are struggling to cope with stressors associated with aging. 


\section{REFERENCES}

Addis, M., \& Linehan, M. M. (1989). Predicting suicidal behavior: Psychometric properties of the Suicidal Behaviors Questionnaire. Poster presented at the annual meeting of the Association for the Advancement of Behavior Therapy, Washington D. C.

Alford, B. A., \& Gerrity, D. M. (1995). The specificity of sociotropy-autonomy personality dimensions to depression vs. anxiety. Journal of Clinical Psychology, 59, 1069-1075.

Bagby, R. M., Gilchrist, E. J., Rector, N. A., Dickens, S. E., Joffe, R. T., Levitt, A., Levitan, R. D., \& Kennedy, S. H. (2001). The stability and validity of the sociotropy and autonomy personality dimensions as measured by the Revised Personal Inventory. Cognitive Therapy and Research, 25, 765-779.

Bandura, A. (2001). Social cognitive theory: An agentic perspective. Annual Review of Psychology, 52, 1-26.

Baron, R. M., \& Kenny, D. A. (1986). The moderator-mediator variable distinction in social psychological research: conceptual, strategic, and statistical considerations. Journal of Personality and Social Psychology, 51, 1173-1182.

Beck, A. T., Epstein, N., \& Harrison, R. (1982). Cognitions, attitudes, and personality dimensions in depression. Paper presented at the annual meeting of the Society for Psychotherapy Research, Smugglers Notch, Vermont, June, 1982.

Beck, A. T., Epstein, N., Harrison, R., \& Emery, G. (1983). Development of the Sociotropy-Autonomy Scale: A measure of personality factors in psychopathology. Unpublished manuscript. University of Pennsylvania: Philadelphia.

Beck, A., \& Steer, R. A. (1991). Manual for the Beck Scale for Suicidal Ideation. San Antonio, TX: The Psychological Corporation.

Beck, A. T., \& Steer, R. A. (1993). Beck Hopelessness Scale: Manual. San Antonio, TX: The Psychological Corporation.

Beck, A. T., Ward, C., \& Mendelson, M. (1961). Beck Depression Inventory (BDI). Archives of General Psychiatry, 4, 561-571.

Bieling, P. J., Beck, A. T., \& Brown, G. K. (2004). Stability and change of sociotropy and autonomy subscales in cognitive therapy of depression. Journal of Cognitive Psychotherapy, 18, 135-148.

Blazer, D. G. (2003). Depression in late life: Review and commentary. Journal of Gerontology: Medical Sciences, 58, 249-265.

Caine, E. D., \& Conwell, Y. (2001). Suicide in the elderly. International Clinical Psychopharmacology, 16, 25-30.

Campbell, D. G., \& Kwon, P. (2001). Domain-specific hope and personal style: Toward an integrative understanding of dysphoria. Journal of Social and Clinical Psychology, 20, 498-520.

Carstensen, L. L., Fung, H. H., \& Charles, S. T. (2003). Socioemotional selectivity theory and the regulation of emotion in the second half of life. Motivation and Emotion, 27, 103-123.

Casey, P., Dunn, G., Kelly, B. D., Lehtinen, V., Dalgard, O. S., Dowrick, C., \& AyusoMateos, J. L. (2008). The prevalence of suicidal ideation in the general 
population: Results from the Outcome of Depression International Network (ODIN) Study. Social Psychiatry and Psychiatric Epidemiology, 43, 299-304.

Center for Disease Control (2005). Web-based injury statistics query and reporting system (WISQARS). National Center for Injury Prevention and Control. Retrieved November 12, 2007, from www.cdc.gov/ncipc/wisqars/default.htm.

Charles, S. T., Reynolds, C. A., \& Gatz, M. (2001). Age-related differences and change in positive and negative affect over 23 years. Journal of Personality and Social Psychology, 80, 136-151.

Clark, D. A., \& Oates, T. (1995). Daily hassles, major and minor life events, and their interaction with sociotropy and autonomy. Behavioral Research and Therapy, 33, 819-823.

Clark, D. C. (1993). Narcissistic crises of aging and suicidal behavior. Suicide and LifeThreatening Behavior, 23, 21-26.

Clark, D. A., Steer, R. A., Haslam, N., Beck, A. T., \& Brown, G. K. (1997). Personality vulnerability, psychiatric diagnoses, and symptoms: Cluster analyses of the Sociotropy-Autonomy subscales. Cognitive Therapy and Research, 21, 267-283.

Cohen, B. (1999). Measuring the Willingness to Seek Help. Journal of Social Service Research, 26, 67-82.

Conwell, Y., \& Brent, D. (1996). Suicide and aging I: Patterns of psychiatric diagnosis. In J. L. Pearson \& Y. Conwell (Eds.), Suicide: International perspectives (pp. 1520). New York: Springer.

Costa, P. T., \& McCrae, R. R. (1992). Revised NEO Personality Inventory (NEO-PI-R) and NEO Five-Factor Inventory (NEO-FFI) manual. Odessa, FL: Psychological Assessment Resources.

Coyne, J. C., \& Whiffen, V. E. (1995). Issues in personality as diathesis for depression: The case of sociotropy-dependency and autonomy-self-criticism. Psychological Bulletin, 118, 358-378.

Cukrowicz, K., Ekblad, A. G., Cheavens, J. S., Rosenthal, M. Z., \& Lynch, T. R. (2008). Coping and thought suppression as predictors of suicidal ideation in depressed older adults with personality disorders. Aging Mental Health, 12, 149-157.

Dasch, K. B., Cohen, L. H., Sahl, J. C., \& Gunthert, K. C. (2008). Moderating effects of sociotropy and autonomy on affective and self-esteem reactivity to daily stressors. Cognitive Therapy and Research, 32, 177-195.

Diener, E., \& Suh, E. (1997). Measuring quality of life: Economic, social, and subjective indicators. Social Indicators Research, 40, 189-216.

Duberstein, P. R. (1996). Openness to experience and completed suicide across the second half of life. In J. L. Pearson, \& Y. Conwell (Eds.), Suicide and aging: International perspectives, pp. 49-64. New York: Springer Publishing Co.

Duberstein, P. R., Conwell, Y., \& Caine, E. D. (1994). Age differences in personality characteristics of completers: Preliminary findings from a psychological autopsy study. Psychiatry, 57, 213-224.

Duberstein, P. R., Conwell, Y., Seidlitz, 1., Denning, D. G., Cox, C., \& Caine, E. D. (2000). Personality traits and suicidal behavior and ideation in depressed inpatients 50 years of age and older. The Journals of Gerontology: Series B: Psychological Sciences and Social Sciences, 55B, 18-26. 
Eaton, W. W., Mutaner, L., Smith, C., Tien, A., \& Ybarra, M. (2004). Center for Epidemiologic Studies Depression Scale: Review and revision (CES-D and CESD-R). In M. E. Maruish (Ed.), The use of psychological testing for treatment planning and outcome assessment: Volume 3: Instruments for adults (pp. 363377). Mahwah, NJ: Lawrence Erlbaum Associates.

Fairbrother, N., \& Moretti, M. (1998). Sociotropy, autonomy, and self-discrepancy: Status in depressed, remitted depressed, and control participants. Cognitive Therapy and Research, 22, 1998.

Fairchild, A. J., MacKinnon, D. P., Torbaga, M. P., \& Taylor, A. B. (2009). $R^{2}$ effect size measures for mediation analysis. Behavior Research Methods, 41, 486-498.

Filiberti, A., Ripamonti, C., Totis, A., Ventafridda, V., De Conno, F., Contiero, P. (2001). Characteristics of terminal cancer patients who committed suicide during a home palliative care program. Journal of Pain and Symptom Management, 22, 544-553.

Fillenbaum, G. G., \& Smyer, M. A. (1981). The development, validity, and reliability of the OARS Mulitdimensional Functional Assessment Questionnaire. Journal of Gerontology, 36, 428-434.

Fiske, A., Wetherell, J. L., \& Gatz, M. (2009). Depression in older adults. Annual Review of Clinical Psychology, 5, 363-389.

Frewen, P. A., \& Dozis, D. J. A. (2006). Social, achievement, and control dimensions of personality-life event vulnerability to depression. Cognitive Therapy and Research, 30, 1-17.

Gatz, M., Johansson, B., Pederson, N., Berg, S., \& Reynolds, C. (1993). A cross-national serlf-report measure of depressive symptomatology. International Psychogeratrics, 5, 147-156.

Hammen, C., Ellicott, A., Gitlin, M., \& Jamison, K. R. (1989) Sociotropy/autonomy and vulnerability to specific life events in patents with unipolar depression and bipolar depression. Journal of Abnormal Psychology, 98, 154-160.

Hasin, D. S., Goodwin, R. D., Stinson, F. S., \& Grant, B. F. (2005). Epidemiology of major depressive disorder: Results from the National Epidemiologic Survey on Alcholism and Related Conditions. Archives of General Psychiatry, 62, 10971106.

Hayes, S. C., Strosahl, K. D., \& Wilson, K. G. (2003). Acceptance and commitment therapy: An experiential approach to behavior change. New York: Guilford Press.

Haynes, T. L., Heckhausen, J., Chipperfield, J. G., Perry, R. P., \& Newall, N. E. (2009). Primary and secondary control strategies: Implication for health and well-being among older adults. Journal of Social and Clinical Psychology, 28, 165-197.

Heckhausen, J. (1997). Developmental regulation across adulthood: Primary and secondary control of age-related challenges. Developmental Psychology, 33, 176187.

Heckhausen, J., Dixon, R. A., \& Baltes, P. B. (1989). Gains and losses in development throughout adulthood as perceived by different adult age groups. Developmental Psychology, 25, 109-121.

Heckhausen, J., \& Schulz, R. (1995). A life-span theory of control. Psychological Review, 102, 284-304. 
Heckhausen, J., Wrosch, C., \& Schulz, R. (2010). A motivational theory of life-span development. Psychological Review, 117, 32-60.

Heisel, M. J., Duberstein, P. R., Conner, K. R., Franus, N., Beckman, A., \& Conwell, Y. (2006). Personality and reports of suicide ideation among depressed adults 50 years of age or older. Journal of Affective Disorders, 90, 175-180.

Heisel, M. J., Links, P. S., Conn, D., van Reekum, R., \& Flett, G. L. (2007). Narcissistic personality and vulnerability to late-life suicidality. The American Journal of Geriatric Psychiatry, 15, 734-741.

Hong, S., Malik, M. L., \& Lee, M. (2003). Testing configural, metric, scalar, and latent mean invariance across genders in sociotropy and autonomy using a non-Western sample. Educational and Psychological Measurement, 63, 636-654.

Husky, M. M., Mazure, C. M., Maciejewski, P. K., \& Swendsen, J. D. (2007). A daily life comparison of sociotropy-autonomy and hopelessness theories of depression. Cognitive Therapy Research, 31, 659-676.

Iacoviello, B. M., Grant, D. A., Alloy, L. B., \& Abramson, L. Y. (2009). Cognitive personality characteristics impact the course of depression: A prospective study of sociotropy, autonomy and domain-specific life events. Cognitive Therapy Research, 33, 187-198.

Isometsä, E. T. (2001). Psychological autopsy studies - A review. European Psychiatry, 16, 379-385.

Kaldenberg, D. O., Koenig, H. F., \& Becker, B. W. (1994). Mail survey response patterns in a population of the elderly: Does response deteriorate with age?. The Public Opinion Quarterly, 58, 68-76.

Kessler, R. C., Berglund, P., Demler, O., Jin, R., Koretz, D., Merikangas, K. R., Rush, A. J., Walters, E. E., \& Wang, P. S. (2003). The epidemiology of Major Depressive Disorder. Journal of the American Medical Association, 289, 3095-3105.

Kessler, R. C., Borges, G., \& Walters, E. E. (1999). Prevalence of risk factors for lifetime suicide attempts in the National Comorbidity Survey. Archives of General Psychiatry, 56, 617-626.

Lichtenstein, P., DeFaire, U., Flodenes, B., Svartengren, M., Svedberg, P., \& Pedersen, N. L. (2002). The Swedish Twin Registry: A unique resource for clinical, epidemiological, and genetic studies. Journal of Internal Medicine, 252, 184.

Linehan, M. (1981). Suicidal behaviors questionnaire. Unpublished inventory. University of Washington, Seattle, WA.

Linehan, M.M., \& Addis, M. (1990). Screening for suicidal behaviors: The Suicidal Behaviors Questionnaire. Unpublished manuscript, University of Washington.

Links, P. S., Heisel, M. J., \& Quastel, A. (2005). Is suicide ideation a surrogate endpoint for geriatric suicide?. Suicide and Life-Threatening Behavior, 35, 193-205.

MacKinnon, D. P., Lockwood, c. M., Hoffman, J. M., West, S. G., \& Sheets, V. (2002). A comparison of methods to test mediation and other intervening variable effects. Psychological Methods, 7, 83-104.

Mazure, C. M., Bruce, M. L., Maciejewski, P. K., \& Jacobs, S. C. (2000). Adverse life events and cognitive-personality characteristics in the prediction of major depression and antidepressant response. American Journal of Psychiatry, 157, 896-903. 
Mazure, C.M., \& Maciejewski, P. K. (2003a). A model of risk for major depression: Effects of life stress and cognitive style vary by age. Depression and Anxiety, 17, 26-33.

Mazure, C. M., \& Maciejewski, P. K. (2003b). The interplay of stress, gender, and cognitive style in depressive onset. Archives of Women's Mental Health, 6, 5-8.

Mazure, C.M., Maciejewski, P.K., Jacobs, S.C., \& Bruce., M.L. (2002). Stressful life events interacting with cognitive/personality styles to predict late-onset major depression. American Journal of Geriatric Psychiatry, 10, 297-304.

McBride, C., Bacchiochi, J. R., \& Bagby, R.M. (2005). Gender differences in the manifestation of sociotropy and autonomy personality traits. Personality and Individual Differences, 38, 129-136.

Mongrain, M., \& Blackburn, S. (2006). Cognitive vulnerability, lifetime risk, and the recurrence of major depression in graduate students. Cognitive Therapy and Research, 29, 747-768.

Morse, J. Q., \& Robins, C. J. (2005). Personality-live event congruence in late-life depression. Journal of Affective Disorders, 84, 25-31.

Nelson, D. R., Hammen, C., Daley, S. E., Burge, D., \& Davila, J. (2001). Sociotropic and autonomous personality styles: Contributions to chronic life stress. Cognitive Therapy and Research, 25, 61-76.

Nordahl, H. M., \& Stiles, T. C. (2007). Personality styles in patients with fibromyalgia, major depression and health controls. Annals of General Psychiatry, 6, 1-6.

O’Carroll, P. W., Berman, A. L., Maris, R. W., Moscicki, E. K., Tanney, B. L., \& Silverman, M. M. (1996). Beyond the Tower of Babel: A nomenclature for suicidology. Suicide and Life-Threatening Behavior, 26, 237-252.

O’Riley, A. A., Nadorff, M., Smith, M., Widoe, R., Forsythe, J., Fiske, A. (April, 2008). The relation between autonomy and suicidal ideation. Poster presented at the 2008 annual meeting of the American Association of Suicidology, Boston, MA.

Osborne, Jason \& Waters, E. (2002). Four assumptions of multiple regression that researchers should always test. Practical Assessment, Research \& Evaluation, 8(2).80-88.

Osman, A., Bagge, C. L., Guitierrez, P. M., Kooper, B. A., Barrios, F. X. (2001). The Suicidal Behaviors Questionnaire - Revised (SBQ-R): Validation with clinical and nonclinical samples. Assessment, 5, 443-454.

Preacher, K. J., \& Hayes, A. F. (2004). SPSS and SAS procedures for estimating indirect effects in simple mediation models. Behavior Research Methods, Instruments and Computers, 36, 717-731.

Radloff, L. S. (1977). The CES-D Scale: A self-report depression scale for research in the general population. Applied Psychological Measurement, 1, 385-401.

Robins, C. J., Bagby, R. M., Rector, N. A., Lynch, T. R., Kennedy, S. H. (1997). Sociotropy, autonomy, and patterns of symptoms in patients with Major Depression: A comparison of dimensional and categorical approaches. Cognitive Therapy and Research, 21, 285-300.

Robins, C. J., Block, P., \& Peselow, E. D. (1989). Relations of sociotropic and autonomous personality characteristics to specific symptoms in depressed patients. Journal of Abnormal Psychology, 98, 86-88. 
Robins, C. J., Hayes, A. M., Block, P., Kramer, R. J., \& Villena, M. (1995). Interpersonal and achievement concerns and the depressive vulnerability and symptom specificity hypotheses: A prospective study. Cognitive Therapy and Research, 19, $1-20$.

Robins, C. J., Ladd, J., Welkowitz, J., Blaney, P. H., Diaz, R, \& Kutcher, G. (1994). The Personal Style Inventory: Preliminary validation studies of new measures of sociotropy and autonomy. Journal of Psychopathology and Behavioral Assessment, 16, 277-300.

Rothbaum, F., Weisz, J. R., \& Snyder, S. S. (1982). Changing the world and changing the self: A two-process model of perceived control. Journal of Personality and Social Psychology, 42, 5-37.

Rowe, J. L., Bruce, M. L., \& Conwell, Y. (2006). Correlates of suicide among home health care utilizers who died by suicide and community controls. Suicide and Life-Threatening Behavior, 36, 65-75.

Şahin, N., Ulusoy, M., \& Şahin, N. (2003). Exploring the sociotropy-autonomy dimensions in a sample of Turkish psychiatric inpatients. Journal of Clinical Psychology, 59, 1055-1068.

Sato, T., \& McCann, D. (2000). Sociotropy-autonomy and the Beck Depression Inventory. European Journal of Psychological Assessment, 16, 66-76.

Schafer, J. L. (1999). Multiple imputation: A primer. Statistical Methods in Medical Research, 8, 3-15

Scogin, F., Welsh, D., Hanson, A., Stump, J., \& Coates, A. (2005). Evidence-based psychotherapies for depression in older adults. Clinical Psychology: Science and Practice, 12, 222-237.

Segal, Z. V., Williams, J. M. G., \& Teasdale, J. D. (2002). Mindfulness-based cognitive therapy for depression. New York: Guilford Press.

Shrout, P. E., \& Bolger, N. (2002). Mediation in experimental and nonexperimental studies: New procedures and recommendations. Psychological Methods, 7, 422445.

Stafford, L., Jackson, H. J., \& Berk, M. (2009). Cognitive-personality style as vulnerability to depression in patients with coronary artery disease: Roles of sociotropy and autonomy. Psychosomatic Medicine, 71, 63-69.

Tabachnick, B. G., \& Fidell, L. S. (2007). Using multivariate statistics. pp. 5-7, 11-12, 27-49, 62-72, \& 441-444. Boston, MA: Pearson Education, Inc.

United States Census Bureau. (2008). American community survey. Retrieved May 8, 2010 from http://factfinder.census.gov/home/saff/main.html?_lang=en.

Useda, J., D., Duberstein, P. R., Conner, K. R., Beckman, A., Franus, N., Tu, X., \& Conwell, C. (2007). Personality differences in attempted suicide versus suicide in adults 50 years of age or older. Journal of Consulting and Clinical Psychology, 75, 126-133.

Waern, M., Beskow, J., Runeson, B., \& Skoog, I. (1999). Suicidal feelings in the last year of life in elderly people who commit suicide. The Lancet, 354, 917-918.

Whitley, B. E. (2002). Survey research. In B. E. Whitney, Principles of research in behavioral science ( $2^{\text {nd }}$ ed. , pp. 343-386). Boston, MA: McGraw Hill. 
Wilson, K. G., Cochinov, H. M., McPherson, C. J., Skirko, M. G., Allard, P., Chary, S., et al. (2007). Desire for euthanasia or physician-assisted suicide in palliative cancer care. Health Psychology, 26, 314-323.

Wrosch, C., Schulz, R., \& Heckhausen, J. (2002). Health stresses and depressive symptomatology in the elderly: The importance of health engagement control strategies. Health Psychology, 21, 340-348.

Wrosch, C., Schulz, R., \& Heckhausen, J. (2004). Health stress and depressive symptomatology in the elderly: A control-process approach. Current Directions in Psychological Science, 13, 17-20.

Voyer, M., \& Cappeliez, P. (2002). Congruency between depressogneic schemas and life events for the prediction of depressive relapse in remitted older adults. Behavioral and Cognitive Psychotherapy, 30, 165-177.

Zuroff, D. C., \& Fitzpatrick, D. K. (1995). Depressive personality styles: Implications for adult attachment. Personality and Individual Differences, 18, 253-265. 
Appendix 1: The CES-D-R

Below is a list of the ways you might have felt or behaved. Please check the boxes to tell me how often you have felt this way in the past week or so.

\begin{tabular}{|c|c|c|c|c|c|}
\hline & \multicolumn{4}{|c|}{ Last Week } & \multirow{2}{*}{$\begin{array}{l}\text { Nearly } \\
\text { Every } \\
\text { Day for } 2 \\
\text { Weeks }\end{array}$} \\
\hline DURING THE PAST WEEK: & $\begin{array}{l}\text { Not at All } \\
\text { or Less } \\
\text { Than } 1 \\
\text { Day }\end{array}$ & 1-2 Days & 3-4 Days & 5-7 Days & \\
\hline \multicolumn{6}{|l|}{ C1. My appetite was poor. } \\
\hline \multicolumn{6}{|l|}{ C2. I could not shake off the blues. } \\
\hline \multicolumn{6}{|c|}{$\begin{array}{l}\text { C3. I had trouble keeping my mind on what I } \\
\text { was doing. }\end{array}$} \\
\hline \multicolumn{6}{|l|}{ C4. I felt depressed. } \\
\hline \multicolumn{6}{|l|}{ C5. My sleep was restless. } \\
\hline \multicolumn{6}{|l|}{ C6. I felt sad. } \\
\hline \multicolumn{6}{|l|}{ C7. I could not get going. } \\
\hline \multicolumn{6}{|l|}{ C8. Nothing made me happy. } \\
\hline \multicolumn{6}{|l|}{ C9. I felt like a bad person. } \\
\hline \multicolumn{6}{|l|}{ C10. I lost interest in my usual activities. } \\
\hline \multicolumn{6}{|l|}{ C11. I slept much more than usual. } \\
\hline \multicolumn{6}{|l|}{ C12. I felt like I was moving too slowly. } \\
\hline \multicolumn{6}{|l|}{ C13. I felt fidgety. } \\
\hline \multicolumn{6}{|l|}{ C14. I wished I were dead. } \\
\hline \multicolumn{6}{|l|}{ C15. I wanted to hurt myself. } \\
\hline \multicolumn{6}{|l|}{ C16. I was tired all the time. } \\
\hline \multicolumn{6}{|l|}{ C17. I did not like myself. } \\
\hline \multicolumn{6}{|c|}{ C18. I lost a lot of weight without trying to. } \\
\hline \multicolumn{6}{|l|}{ C19. I had a lot of trouble getting to sleep. } \\
\hline $\begin{array}{l}\text { C20. I could not focus on the important } \\
\text { things. }\end{array}$ & & & & & \\
\hline
\end{tabular}




\section{Appendix 2: OMFAQ}

The following questions ask you a little about activities you have to do in your daily life. For each activity, please place a check in the appropriate box based upon whether you cannot perform the activity, you can perform the activity with some help, or you can perform the activity without any help.

\begin{tabular}{|c|c|c|c|}
\hline & $\begin{array}{l}\text { I cannot } \\
\text { perform this } \\
\text { activity. }\end{array}$ & $\begin{array}{l}\text { I can perform } \\
\text { this activity } \\
\text { with some } \\
\text { help. }\end{array}$ & $\begin{array}{l}\text { I can perform } \\
\text { this activity } \\
\text { without any } \\
\text { help. }\end{array}$ \\
\hline \multicolumn{4}{|l|}{ A1. Can use the telephone? } \\
\hline \multicolumn{4}{|l|}{$\begin{array}{l}\text { A2. Can you get to places that are } \\
\text { not within walking distance (i.e. } \\
\text { driving, public transportation)? }\end{array}$} \\
\hline \multicolumn{4}{|l|}{ A3. Can you manage your money? } \\
\hline \multicolumn{4}{|l|}{$\begin{array}{l}\text { A4. Can you take your medicine } \\
\text { correctly? }\end{array}$} \\
\hline \multicolumn{4}{|l|}{$\begin{array}{l}\text { A5. Can you do your grocery } \\
\text { shopping? }\end{array}$} \\
\hline \multicolumn{4}{|l|}{ A6. Can you prepare your meals? } \\
\hline \multicolumn{4}{|l|}{$\begin{array}{l}\text { A7. Can you take care of your } \\
\text { housework? }\end{array}$} \\
\hline \multicolumn{4}{|l|}{$\begin{array}{l}\text { A8. Can you do the basic } \\
\text { maintenance in your home? }\end{array}$} \\
\hline \multicolumn{4}{|l|}{ A9. Can you feed yourself? } \\
\hline \multicolumn{4}{|l|}{ A10. Can you dress and undress? } \\
\hline \multicolumn{4}{|l|}{$\begin{array}{l}\text { A11. Can you take care of your } \\
\text { appearance (e.g. comb your hair)? }\end{array}$} \\
\hline \multicolumn{4}{|l|}{ A12. Can you do laundry? } \\
\hline \multicolumn{4}{|l|}{ A13. Can you walk? } \\
\hline \multicolumn{4}{|l|}{$\begin{array}{l}\text { A14. Can you walk up and down } \\
\text { stairs? }\end{array}$} \\
\hline \multicolumn{4}{|l|}{ A15. Can you get in and out of bed? } \\
\hline \multicolumn{4}{|l|}{$\begin{array}{l}\text { A16. Can you get in and out of the } \\
\text { bathtub? }\end{array}$} \\
\hline \multicolumn{4}{|l|}{ A17. Can you shower or bathe? } \\
\hline $\begin{array}{l}\text { A18. Can you stand up if you have } \\
\text { been seated on an ordinary chair } \\
\text { without arms? }\end{array}$ & & & \\
\hline
\end{tabular}




\begin{tabular}{|l|l|l|l|}
\hline & $\begin{array}{l}\text { I cannot } \\
\text { perform this } \\
\text { activity. }\end{array}$ & $\begin{array}{l}\text { I can perform } \\
\text { this activity } \\
\text { with some } \\
\text { help. }\end{array}$ & $\begin{array}{l}\text { I can perform } \\
\text { this activity } \\
\text { without any } \\
\text { help. }\end{array}$ \\
\hline $\begin{array}{l}\text { A19. Can you reach above shoulder } \\
\text { height? }\end{array}$ & $\begin{array}{l}\text { A20. Can you bend down to pick up } \\
\text { something from the floor? }\end{array}$ & & \\
\hline $\begin{array}{l}\text { A21. Can you manage small things } \\
\text { with your fingers (e.g. writing)? }\end{array}$ & & & \\
\hline
\end{tabular}


Appendix 3: The Personal Style Inventory - Autonomy Subscale

\section{Perfectionism/Self-Criticism}

1. It bothers me when I feel that I am only average and ordinary.

SD D SD SA A SA

4. I usually view my performance as either a complete success or a complete failure.

SD D SD SA A SA

7. I feel badly about myself when I am not actively accomplishing things.

10. I have a hard time forgiving myself when I feel I haven't

$$
\text { SD D SD SA A SA }
$$
worked up to my potential.

\section{Need for Control}

SD D SD SA A SA

2. I am easily bothered by other people making demands on me.

5. In relationships, people are often too demanding of one

SD D SD SA A SA another.

8. It is hard for me to take instructions from people who have authority over me.

11. It is hard for me to have someone dependent on me.

SD D SD SA A SA

13. I resent it when people try to direct my behaviors or activities.

SD D SD SA A SA SD D SD SA A SA

SD D SD SA A SA

15. I am very upset when other people or circumstances interfere with my plans.

17. I become upset more than most people I know when

SD D SD SA A SA limits are placed on my personal independence and freedom.

19. I feel controlled when others have a say in my plans.

SD D SD SA A SA

SD D SD SA A SA

Defensive Separation

3. I tend to keep other people at a distance.

6. I don't like relying on others for help.

SD D SD SA A SA

SD D SD SA A SA

9. When I'm feeling blue, I don't like to be offered sympathy.

12. I don't like people to invade my privacy.

SD D SD SA A SA

SD D SD SA A SA

14. I often handle big decisions without telling anyone else about them. 
SD D SD SA A SA

16. It is hard for me to express admiration or affection.

SD D SD SA A SA

18. It is difficult for me to make a long-term commitment to a relationship.

20. It is hard for me to open up and talk about my feelings and other personal things.

21. When making a big decision, I usually feel that advice from others is intrusive.

22. Personal questions from others usually feel like an invasion

SD D SD SA A SA

SD D SD SA A SA of my privacy.

SD D SD SA A SA

SD D SD SA A SA

23. I rarely trust the advice of others when making a big decision.

SD D SD SA A SA

24. I become upset when others try to influence my thinking on a problem.

SD D SD SA A SA 
Appendix 4: The WSH

Please read each item carefully and place an X in the appropriate column.

\begin{tabular}{|c|c|c|c|c|}
\hline & $\begin{array}{l}\text { Strongly } \\
\text { Disagree }\end{array}$ & Disagree & Agree & $\begin{array}{l}\text { Strongly } \\
\text { Agree }\end{array}$ \\
\hline $\begin{array}{l}\text { H1. If I were afraid of heights, I would try to conceal this } \\
\text { from my friends. }\end{array}$ & & & & \\
\hline $\begin{array}{l}\text { H2. No conflict in our marriage could be so severe that } \\
\text { my partner and I could not solve it on our own. }\end{array}$ & & & & \\
\hline $\begin{array}{l}\text { H3. Were a problem to develop in my sex life, I would } \\
\text { either need to solve it alone or to live with it, because I } \\
\text { would not be able to discuss it with anyone. }\end{array}$ & & & & \\
\hline $\begin{array}{l}\text { H4. If, for whatever reason, I were to have prolonged } \\
\text { difficulty walking, I would do whatever possible to } \\
\text { avoid asking help from anyone. }\end{array}$ & & & & \\
\hline $\begin{array}{l}\text { H5. When something breaks down in my home, I usually } \\
\text { persist in trying to fix it myself, even when it is difficult } \\
\text { and I am wasting time and money. }\end{array}$ & & & & \\
\hline $\begin{array}{l}\text { H6. If I were suddenly afraid to go in the street, I believe } \\
\text { I could overcome without help from anyone else. }\end{array}$ & & & & \\
\hline $\begin{array}{l}\text { H7. If a serious problem were to arise in my marriage, I } \\
\text { would be willing to talk about it with a professional, or } \\
\text { with a friend or relative, but in any case I would not } \\
\text { keep it to myself. }\end{array}$ & & & & \\
\hline $\begin{array}{l}\text { H8. Sexual problems are a difficult problem to talk } \\
\text { about, but if I were to have such a problem I would use } \\
\text { the services of an expert. }\end{array}$ & & & & \\
\hline $\begin{array}{l}\text { H9. If I ever have difficulty seeing, I will try to arrange } \\
\text { my life so no one will notice. }\end{array}$ & & & & \\
\hline $\begin{array}{l}\text { H10. If I were to lose control and hurt my child in a } \\
\text { moment of anger, I would need to make sure that no one } \\
\text { would know about it. }\end{array}$ & & & & \\
\hline $\begin{array}{l}\text { H11. Discovering unexpectedly that my spouse was } \\
\text { hitting my child would lead me to seek out someone } \\
\text { who could intervene as quickly as possible. }\end{array}$ & & & & \\
\hline
\end{tabular}




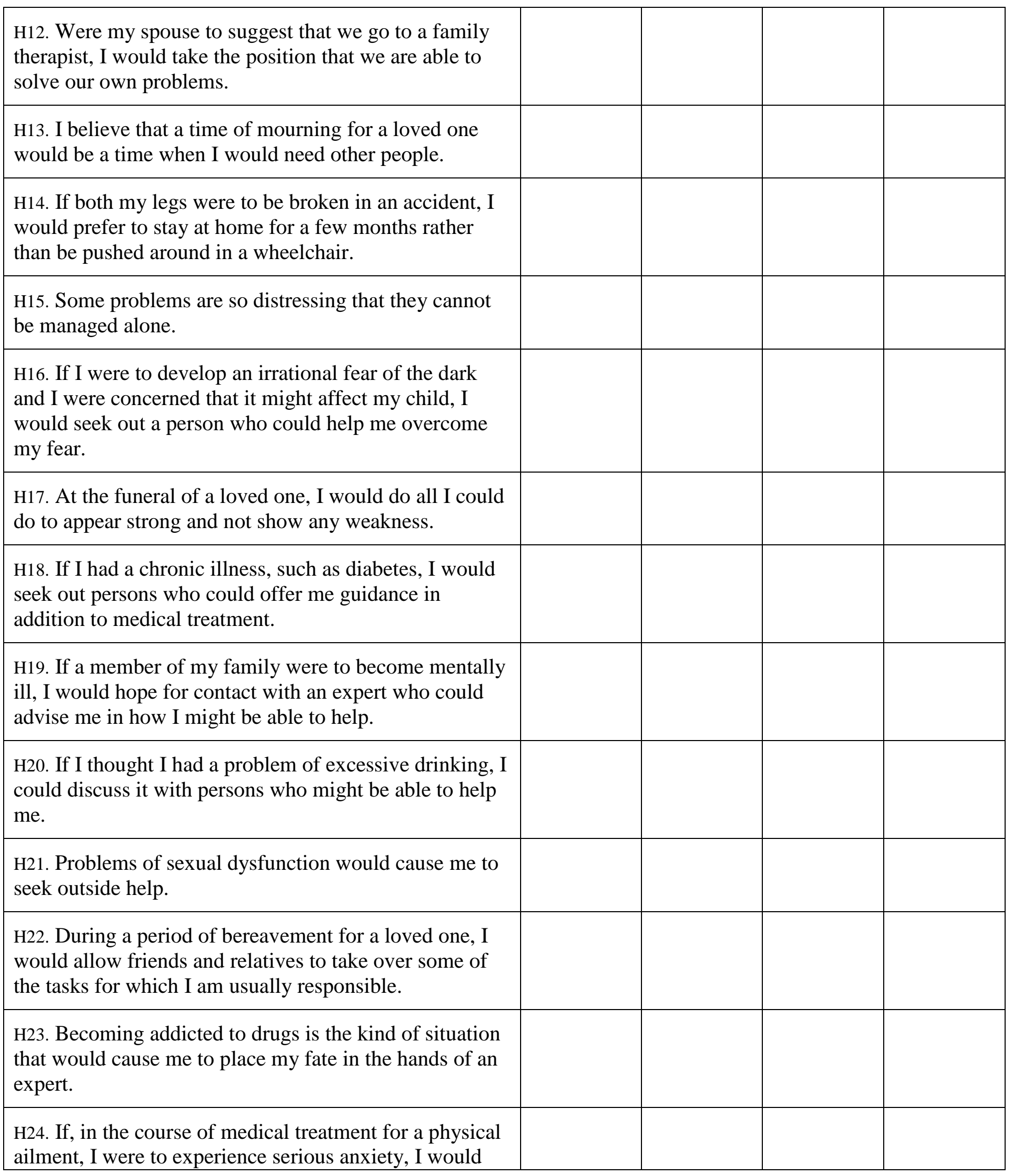


ask the doctor to treat the anxiety.

H25. If I am ever depressed, I will seek out the appropriate person to tell about it. 
Appendix 5: The SBQ-14

In the previous sections, we have asked about some of your general thoughts and behaviors. The following questions ask about a specific topic - whether you have ever thought about suicide. Many people have had thoughts about suicide. Please answer honestly. Your responses will be kept confidential.

NOTE: A list of mental health agencies that can help individuals having thoughts of suicide is included at the end of this survey.

S1. Have you thought about or attempted to kill yourself in your lifetime?
a. No
b. It was just a passing thought.
c. I briefly considered it, but not seriously.
d. I thought about it and was somewhat serious.
e. I had a plan for killing myself which I thought would work and seriously considered it.
f. I attempted to kill myself, but I do not think I really meant to die.
g. I attempted to kill myself, and I think I really hoped to die.

S2. How often have you thought about killing yourself in your lifetime?
a. Not at all
b. Rarely
c. Sometimes
d. Often
e. Very often

S3. How often have you thought about killing yourself in the last year?
a. Not at all
b. Rarely
c. Sometimes
d. Often
e. Very often

S3. Have you ever told someone that you were going to commit suicide, or that you might do it in your lifetime?
a. No
b. Yes, during one short time period
c. Yes, during more than one short time period 
S4. Have you ever told someone that you were going to commit suicide, or that you might do it in the last year?
a. No
b. Yes, during one short time period
c. Yes, during more than one short time period

S5. What chance is there that you will consider the possibility, no matter how remote, of killing yourself in your lifetime?
a. No chance at all
b. Some chance
c. Very likely

S6. What chance is there that you will consider the possibility, no matter how remote, of killing yourself within the next year?
a. No chance at all
b. Some chance
c. Very likely

S7. How likely is it that you will attempt suicide in your lifetime?
a. No chance at all
b. Some chance
c. Very likely

S8. How likely is it that you will attempt suicide within the next year?
a. No chance at all
b. Some chance
c. Very likely

S9. If you did attempt suicide, for any reason, how likely is it that you would die as a result in your lifetime?
a. No chance at all
b. Some chance
c. Very likely

S10. If you did attempt suicide, for any reason, how likely is it that you would die as a result within the next year?
a. No chance at all
b. Some chance
c. Very likely 
S11. Do you currently have a plan for how you would go about killing yourself, if you decided to do it?
a. No
b. Yes, a vague plan
c. Yes, a definite plan

S12. Some individuals say that they cannot even imagine or conceive of the idea of attempting or committing suicide. For these people, suicidal behavior is as alien as the thought of becoming a tree or lifting the Empire State Building. Other people, even though they might never actually consider the idea, can at least imagine the idea of attempting or considering suicide. Which group of people do you belong to?
a. Group who definitely can't imagine
b. Group who can somewhat imagine
c. Group who can definitely imagine

S13. Would any of your problems be solved if you committed suicide?
a. No, definitely not
b. Maybe
c. Yes, definitely 
Table 1

Demographics of Sample

\begin{tabular}{|c|c|c|c|}
\hline & & Frequency & Valid Percent \\
\hline \multicolumn{4}{|l|}{ Gender } \\
\hline & Male & 45 & 52.9 \\
\hline & Female & 40 & 47.1 \\
\hline \multicolumn{4}{|l|}{ Ethnicity } \\
\hline & White & 82 & 95.3 \\
\hline & African American & 3 & 3.5 \\
\hline & Native American & 1 & 1.2 \\
\hline \multicolumn{4}{|l|}{ Marital Status } \\
\hline & Single & 4 & 4.7 \\
\hline & Married & 47 & 54.7 \\
\hline & Separated & 1 & 1.2 \\
\hline & Divorced & 7 & 8.1 \\
\hline & Widowed & 27 & 31.4 \\
\hline \multicolumn{4}{|l|}{ Rurality } \\
\hline & Rural & 19 & 22.6 \\
\hline & Small Town & 25 & 29.8 \\
\hline & Town & 27 & 32.1 \\
\hline & Large City & 13 & 15.5 \\
\hline \multicolumn{4}{|l|}{ Education } \\
\hline & GED & 3 & 3.5 \\
\hline & High School & 22 & 25.6 \\
\hline & Some College & 21 & 24.4 \\
\hline & College Degree & 23 & 26.7 \\
\hline & Other & 17 & 19.8 \\
\hline \multicolumn{4}{|l|}{ Income } \\
\hline & Less than 10,000 & 3 & 3.8 \\
\hline & $10,000-14,999$ & 7 & 9 \\
\hline & $15,000-24,999$ & 11 & 14.1 \\
\hline & $25,000-34,999$ & 12 & 15.4 \\
\hline & $35,000-49,999$ & 10 & 12.8 \\
\hline & $50,000-74,999$ & 11 & 14.1 \\
\hline & $75,000-99,999$ & 8 & 10.3 \\
\hline & $100,000-149,999$ & 8 & 10.3 \\
\hline & $150,000-199,999$ & 3 & 3.8 \\
\hline & $200,000+$ & 2 & 2.6 \\
\hline & Do Not Know & 3 & 3.8 \\
\hline \multicolumn{4}{|l|}{ Occupation } \\
\hline & Working Full-time & 4 & 4.7 \\
\hline & Working Part-time & 12 & 14.1 \\
\hline & Homemaker & 2 & 2.4 \\
\hline & Unemployed & 1 & 1.2 \\
\hline
\end{tabular}


Retired

Disabled
64

2
75.3

2.4 
Table 2

Descriptive Statistics for the Variables of Interest in the Present Study

\begin{tabular}{cccc}
\hline Measures & $\begin{array}{c}\text { Total }(N=88)^{*} \\
M(S D)\end{array}$ & $\begin{array}{c}\text { Men }(N=40)^{*} \\
M(S D)\end{array}$ & $\begin{array}{c}\text { Women }(N=38)^{*} \\
M(S D)\end{array}$ \\
\hline PSI-II & $72.40(14.51)$ & $71.97(15.51)$ & $72.82(14.89)$ \\
PSI-II & $23.26(5.46)$ & $23.26(6.26)$ & $23.89(5.39)$ \\
$\begin{array}{c}\text { Need for Control } \\
\text { PSI-II } \\
\text { Perfectionism } \\
\text { PSI-II } \\
\begin{array}{c}\text { Defensive } \\
\text { Separation } \\
\text { SBQ }\end{array}\end{array}$ & $12.09(4.19)$ & $11.88(3.62)$ & $12.15(4.54)$ \\
OMFAQ & $37.06(8.15)$ & $38.00(9.61)$ & $37.42(8.07)$ \\
WSH & $15.32(2.80)$ & $16.53(4.49)$ & $15.42(3.35)$ \\
CES-D-R & $60.96(6.32)$ & $61.09(6.41)$ & $60.95(3.12)$ \\
& $25.30(6.57)$ & $26.86(6.19)$ & $22.61(6.22)$ \\
& $7.00(8.98)$ & $6.63(7.55)$ & $7.63(9.26)$ \\
& & &
\end{tabular}

Note: $*$ Because of missing data, sample sizes varied for each analysis; PSI-II = Personal Style Inventory - Revised, Autonomy Subscale; SBQ = Suicidal Behaviors Questionnaire; OMFAQ = OARS Multidimensional Functional Assessment Question; WSH = Willingness to Seek Help (reverse scored); CES-D-R = Center for Epidemiological Studies Depression Scale - Revised 
Table 3

Pearson's Correlations (r) for the Variables of Interest in the Present Study

\begin{tabular}{|c|c|c|c|c|c|c|c|c|}
\hline Measures & $\begin{array}{c}\text { PSI- } \\
\text { II }\end{array}$ & $\begin{array}{l}\text { PSI-II } \\
\text { Need } \\
\text { for } \\
\text { Control }\end{array}$ & $\begin{array}{c}\text { PSI-II } \\
\text { Perfectionism }\end{array}$ & $\begin{array}{c}\text { PSI-II } \\
\text { Defensive } \\
\text { Separation }\end{array}$ & SBQ & OMFAQ & $\begin{array}{c}\text { CES-D- } \\
\text { R }\end{array}$ & WSH \\
\hline PSI-II & - & - & - & - & .007 & -.14 & $.45^{*}$ & $.47 *$ \\
\hline $\begin{array}{c}\text { PSI-II } \\
\text { Need for } \\
\text { Control }\end{array}$ & - & - & $.47 *$ & $.43^{*}$ & -.17 & -.15 & $.37 *$ & $.44 *$ \\
\hline $\begin{array}{c}\text { PSI-II } \\
\text { Perfectionism }\end{array}$ & - & - & - & $.54 *$ & .04 & -.11 & $.65^{*}$ & $.34 *$ \\
\hline $\begin{array}{c}\text { PSI-II } \\
\text { Defensive } \\
\text { Separation }\end{array}$ & - & - & - & - & -.15 & -.06 & $.29 *$ & $.34 *$ \\
\hline SBQ & - & - & - & - & - & .21 & .07 & .03 \\
\hline OMFAQ & - & - & - & - & - & - & $-.31 *$ & -.10 \\
\hline CES-D-R & - & - & - & - & - & - & - & .23 \\
\hline
\end{tabular}

Note: $p<.05$; PSI-II = Personal Style Inventory - Revised, Autonomy Subscale; SBQ = Suicidal Behaviors Questionnaire; OMFAQ = OARS Multidimensional Functional Assessment Question; WSH = Willingness to Seek Help (reverse scored); CES-D-R = Center for Epidemiological Studies Depression Scale - Revised 
Table 4

Percentage of Missing Data for Each Variable of Interest

\begin{tabular}{cc}
\hline Variable & Percentage of Data Missing \\
\hline PSI -II & 14.8 \\
SBQ & 10.2 \\
OMFAQ & 8.0 \\
WSH & 29.5 \\
CES-D-R & 21.6 \\
\hline
\end{tabular}

Note: PSI-II = Personal Style Inventory - Revised, Autonomy Subscale; SBQ = Suicidal

Behaviors Questionnaire; OMFAQ = OARS Multidimensional Functional Assessment

Question; WSH = Willingness to Seek Help (reverse scored); CES-D-R = Center for Epidemiological Studies Depression Scale - Revised 
Table 5

Independent Samples t-tests Examining whether Participants with Missing Data had Significantly Different Total Scores on the Variables of Interest

\begin{tabular}{|c|c|c|c|c|c|}
\hline \multirow{4}{*}{ WSH } & & $M$ & $S D$ & $t$ & $\mathrm{df}$ \\
\hline & & & & .00 & 60 \\
\hline & Missing & 25.00 & 6.44 & & \\
\hline & No Missing & 25.00 & 6.63 & & \\
\hline \multirow[t]{3}{*}{ PSI-II } & & & & .12 & 73 \\
\hline & Missing & 71.67 & 19.33 & & \\
\hline & No Missing & 72.16 & 14.13 & & \\
\hline \multirow[t]{3}{*}{ CESD-R } & & & & .03 & 67 \\
\hline & Missing & 6.94 & 6.72 & & \\
\hline & No Missing & 7.02 & 8.61 & & \\
\hline \multirow[t]{3}{*}{ SBQ-14 } & & & & 1.71 & 77 \\
\hline & Missing & 17.00 & 5.36 & & \\
\hline & No Missing & 15.40 & 2.40 & & \\
\hline \multirow[t]{3}{*}{ OMFAQ } & & & & .30 & 79 \\
\hline & Missing & 61.28 & 2.66 & & \\
\hline & No Missing & 60.92 & 6.07 & & \\
\hline
\end{tabular}

Note. ${ }^{*} p<.05 ;$ PSI-II = Personal Style Inventory - Revised, Autonomy Subscale; SBQ = Suicidal Behaviors Questionnaire; OMFAQ = OARS Multidimensional Functional Assessment Question; WSH = Willingness to Seek Help (reverse scored); CES-D-R = Center for Epidemiological Studies Depression Scale - Revised 
Table 6

Chi-Square Test of Independence Examining whether Participants with Missing Data were Significantly Different in terms of Demographics

\begin{tabular}{|c|c|c|c|c|c|}
\hline & & $\begin{array}{c}\text { Missing } \\
\text { Data }\end{array}$ & $\begin{array}{c}\text { No Missing } \\
\text { Data }\end{array}$ & $X^{2}$ & df \\
\hline Age & $\begin{array}{l}65-74 \\
75-84 \\
85+\end{array}$ & $\begin{array}{c}18 \\
10 \\
4 \\
\end{array}$ & $\begin{array}{c}28 \\
22 \\
4 \\
\end{array}$ & 1.12 & 2 \\
\hline Ethnicity & $\begin{array}{l}\text { White } \\
\text { African } \\
\text { American } \\
\text { Native } \\
\text { American }\end{array}$ & $\begin{array}{c}31 \\
1 \\
0\end{array}$ & $\begin{array}{c}51 \\
2 \\
1\end{array}$ & .62 & 2 \\
\hline Rurality & $\begin{array}{l}\text { Rural } \\
\text { Small Town } \\
\text { Town } \\
\text { Large City }\end{array}$ & $\begin{array}{c}8 \\
7 \\
10 \\
5\end{array}$ & $\begin{array}{c}11 \\
18 \\
17 \\
8\end{array}$ & 1.05 & 3 \\
\hline Education & $\begin{array}{l}\text { GED } \\
\text { High School } \\
\text { Some College } \\
\text { College Degree } \\
\text { Other }\end{array}$ & $\begin{array}{c}2 \\
13 \\
6 \\
5 \\
6 \\
\end{array}$ & $\begin{array}{c}1 \\
9 \\
15 \\
18 \\
11\end{array}$ & 8.68 & 4 \\
\hline Income & $\begin{array}{l}\text { Less than } 10,000 \\
10,000-14,999 \\
15,000-24,999 \\
25,000-34,999 \\
35,000-49,999 \\
50,000-74,999 \\
75,000-99,999 \\
100,000-149,999 \\
150,000-199,999 \\
200,000+ \\
\text { Do Not Know }\end{array}$ & $\begin{array}{l}3 \\
3 \\
5 \\
5 \\
4 \\
4 \\
3 \\
1 \\
1 \\
0 \\
0\end{array}$ & $\begin{array}{l}0 \\
4 \\
6 \\
7 \\
6 \\
7 \\
5 \\
7 \\
2 \\
2 \\
3\end{array}$ & 10.69 & 10 \\
\hline
\end{tabular}

Note. ${ }^{*} p<.05$ 
Table 7

Simple Linear Regression Examining Whether Autonomy Predicts Suicidal Ideation (N =69)

\begin{tabular}{|c|c|c|c|}
\hline Variable & $\beta$ & $b$ & $S E$ \\
\hline \multirow{4}{*}{$\begin{array}{c}\text { PSI-II } \\
\text { SBQ }\end{array}$} & .01 & .002 & .03 \\
\hline & & & \\
\hline & & & Intercept $=15.83$ \\
\hline & & & $R^{2}=.00$ \\
\hline
\end{tabular}


Table 8

Multiple Linear Regression Examining Whether Need for Control, Defensive Separation, and Perfectionism Predict Suicidal Ideation ( $\mathrm{N}=69)$

\begin{tabular}{cccc}
\hline Variable & $\beta$ & $b$ & $S E$ \\
\hline Need for Control & $.35^{*}$ & $.23^{*}$ & .10 \\
Defensive Separation & -.15 & -.07 & .07 \\
Perfectionism & -.01 & -.01 & .14 \\
& & & Intercept $=12.99$ \\
& & & $R^{2}=.08$ \\
\hline
\end{tabular}

Note. ${ }^{*} p<.05 ; \mathrm{SBQ}=$ Suicidal Behaviors Questionnaire 
Table 9

Multiple Linear Regression Examining Whether Need for Control is a Stronger Predictor of Suicidal Ideation in Older Adults with Higher Levels of Functional Impairment ( $\mathrm{N}=$ 69)

\begin{tabular}{ccc}
\hline Variable & $b$ & $S E$ \\
\hline NFC & $.18^{*}$ & .10 \\
OMFAQ & .08 & .14 \\
OMFAQ*NFC & .01 & .78 \\
& & Intercept $=15.94$ \\
& & $\mathrm{R}^{2}=.09$ \\
\hline
\end{tabular}

Note. $* p<.05 ; \mathrm{NFC}=$ Need for Control; OMFAQ $=$ OARS Multidimensional

Functional Assessment Question; SBQ = Suicidal Behaviors Questionnaire 
Table 10

Summary of Mediation Results for Hypothesis 3

\begin{tabular}{cccccccc}
\hline $\begin{array}{c}\text { Independent } \\
\text { Variable (IV) }\end{array}$ & $\begin{array}{c}\text { Mediating } \\
\text { Variable (M) }\end{array}$ & $\begin{array}{c}\text { Dependent } \\
\text { Variable } \\
(\mathrm{DV})\end{array}$ & $\begin{array}{c}\text { Effect } \\
\text { of IV } \\
\text { on M } \\
(a)\end{array}$ & $\begin{array}{c}\text { Effect } \\
\text { of M on } \\
\text { DV }(b)\end{array}$ & $\begin{array}{c}\text { Direct } \\
\text { Effects } \\
\left(c^{\prime}\right)\end{array}$ & $\begin{array}{c}\text { Indirect } \\
\text { Effect } \\
(a \times b)\end{array}$ & $\begin{array}{c}\text { Total } \\
\text { Effects } \\
(c)\end{array}$ \\
\hline NFC & WSH & SBQ & $.52^{*}$ & .05 & .05 & .02 & .08 \\
\hline
\end{tabular}

Note. ${ }^{*} p<.05 ; \mathrm{NFC}=$ Need for Control; WSH $=$ Willingness to Seek Help (reverse scored); SBQ = Suicidal Behaviors Questionnaire 
Table 11

Basic Descriptive Statistics and Correlations for Hypothesis 4 ( $\mathrm{N}=38$ Women, 40 Men)

\begin{tabular}{|c|c|c|c|c|}
\hline \multirow[t]{2}{*}{ Variable } & \multicolumn{2}{|c|}{$\begin{array}{l}r \text { for } \\
\text { Men }\end{array}$} & \multicolumn{2}{|c|}{$\begin{array}{c}r \text { for } \\
\text { Women }\end{array}$} \\
\hline & NFC & SBQ & NFC & SBQ \\
\hline NFC & & .22 & & $.33 *$ \\
\hline SBQ & .22 & & $.33^{*}$ & \\
\hline
\end{tabular}


Table 12

Simple Linear Regression Examining Whether Gender Predicts Suicidal Ideation ( $\mathrm{N}=$ 69)

\begin{tabular}{|c|c|c|c|}
\hline Variable & $\beta$ & $b$ & $S E$ \\
\hline \multirow[t]{3}{*}{$\begin{array}{c}\text { Gender } \\
\text { SBQ }\end{array}$} & -.14 & -1.10 & .90 \\
\hline & & & Intercept $=16.53$ \\
\hline & & & $R^{2}=.02$ \\
\hline
\end{tabular}

Note. ${ }^{*} p<.05 ; \mathrm{SBQ}=$ Suicidal Behaviors Questionnaire 
Table 13

Hierarchical Regression Examining Whether Need for Control Predicts Suicidal Ideation in Older Adults When Controlling for Depression ( $\mathrm{N}=63)$

\begin{tabular}{ccccc}
\hline & Variable & $\beta$ & $b$ & $S E$ \\
\hline Step 1 & CES-D-R & .18 & .49 & .33 \\
& & & \\
& & Intercept $=14.89$ \\
& $R^{2}=.03$ & \\
\hline Step 2 & CES-D-R & .10 & .27 & .36 \\
& NFC & .22 & .15 & .09 \\
& & \\
& & Intercept $=11.95$ & \\
& & $R^{2}=.07$ \\
& &
\end{tabular}

Note. $* p<.05 ; \mathrm{NFC}=$ Need for Control; CES-D-R = Center for Epidemiological Studies Depression Scale - Revised 


\section{Figure Captions}

Figure 1. The developmental trajectory of primary and secondary control striving presented in the Motivational Theory of Life-Span Development (adapted from Heckhausen et al., 2010). In this representation, as people age, their ability to successfully engage in primary control behaviors decreases. Thus, secondary control behaviors increase with age. Successful aging mandates that primary control behaviors are maintained across the life-span (and, if individuals continue to use secondary control behaviors, they will be willing to continue to attempt primary behaviors).

Figure 2. A behavioral model of onset and maintenance of late life depression (adapted from Fiske et al., 2009). In this model, stressful life events and/or physical declines might lead someone with certain long-standing vulnerabilities to begin limiting his or her activities. In a traditional behavioral model of depression, limiting activities is problematic because it results in fewer opportunities for interactions with the environment that have positive outcomes. A lack of positive interactions might result in depression. Depression might lead to in an increase in self-critical cognitions, which might provide a rationale for not engaging in future activities and a vicious cycle develops.

Figure 3. In this diathesis-stress model of late life suicide, normal stressors associated with aging interact with distal risk factors that precipitate distress. If the distress is left untreated, more severe pathology might develop, which might, in certain susceptible individuals, lead to suicidal behavior.

Figure 4. Mediational model for Hypothesis 3. Model predicts that willingness to seek help will partially mediate the relation between need for control and suicidal ideation in older adults.

Figure 5. Mediational model for Hypothesis 4. Model predicts that need for control will partially mediate the relation between gender and suicidal ideation in older adults. 


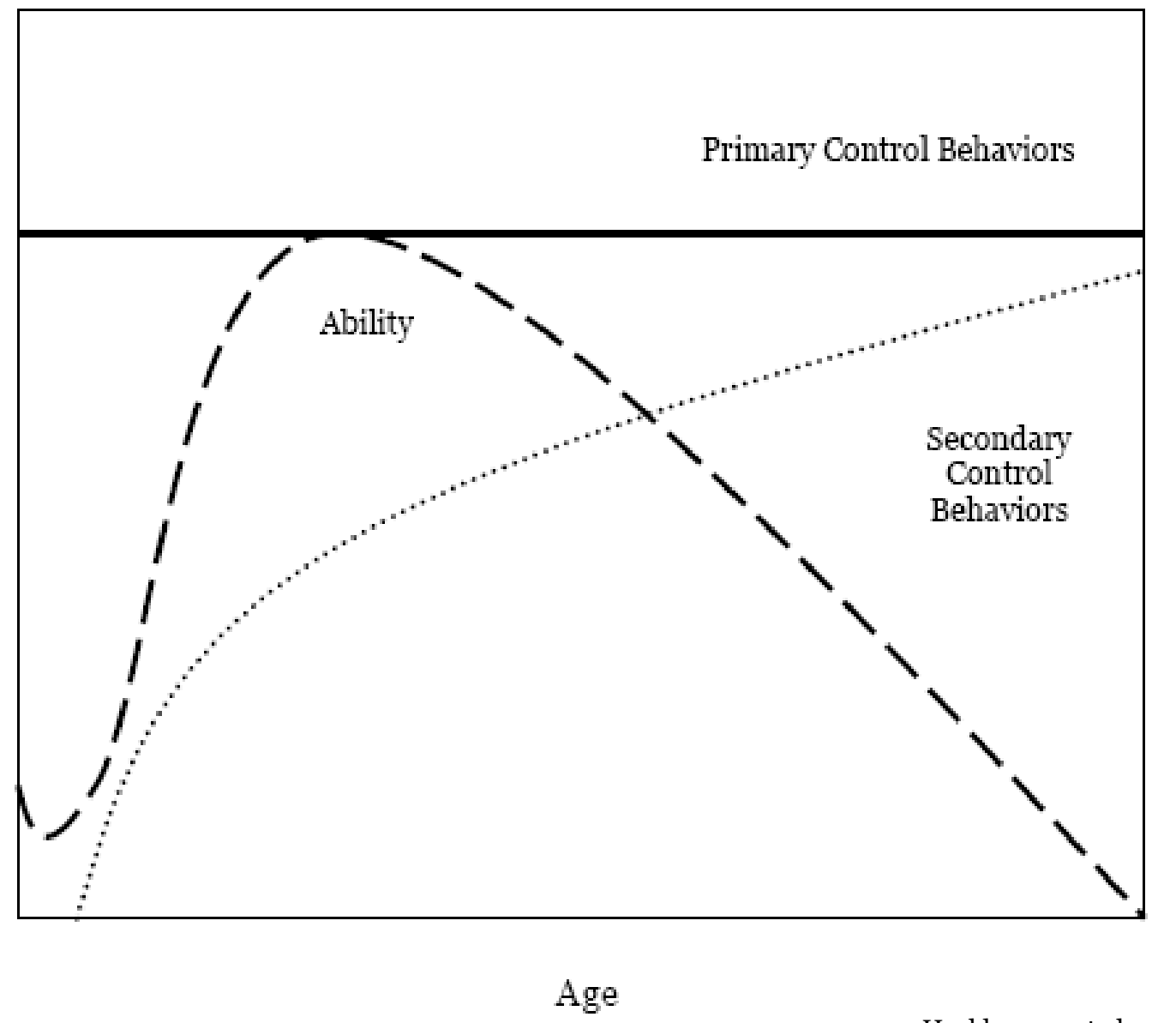

Heckhausen et al., 2010 
Fiske et al., 2009

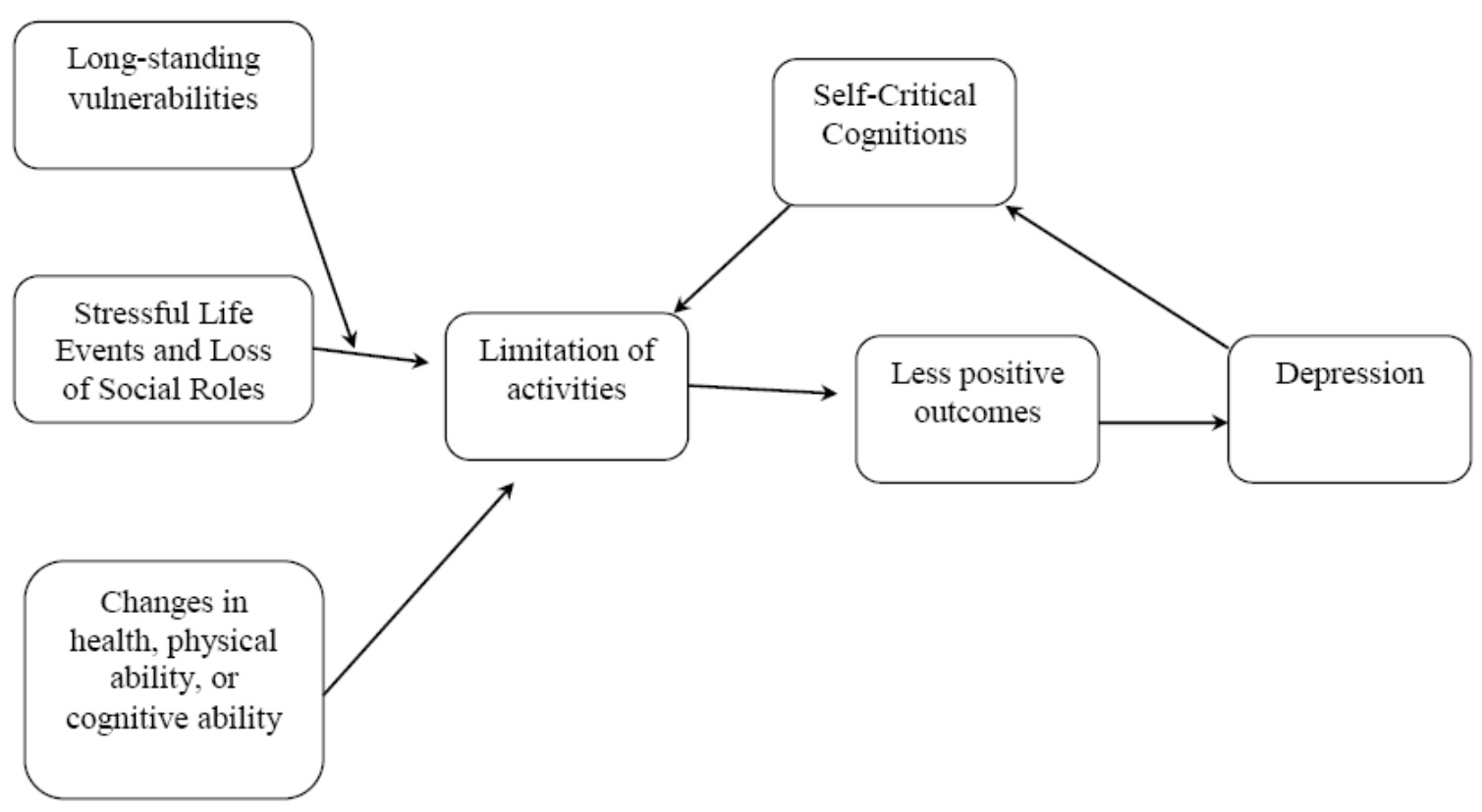




\section{Targets for Prevention}

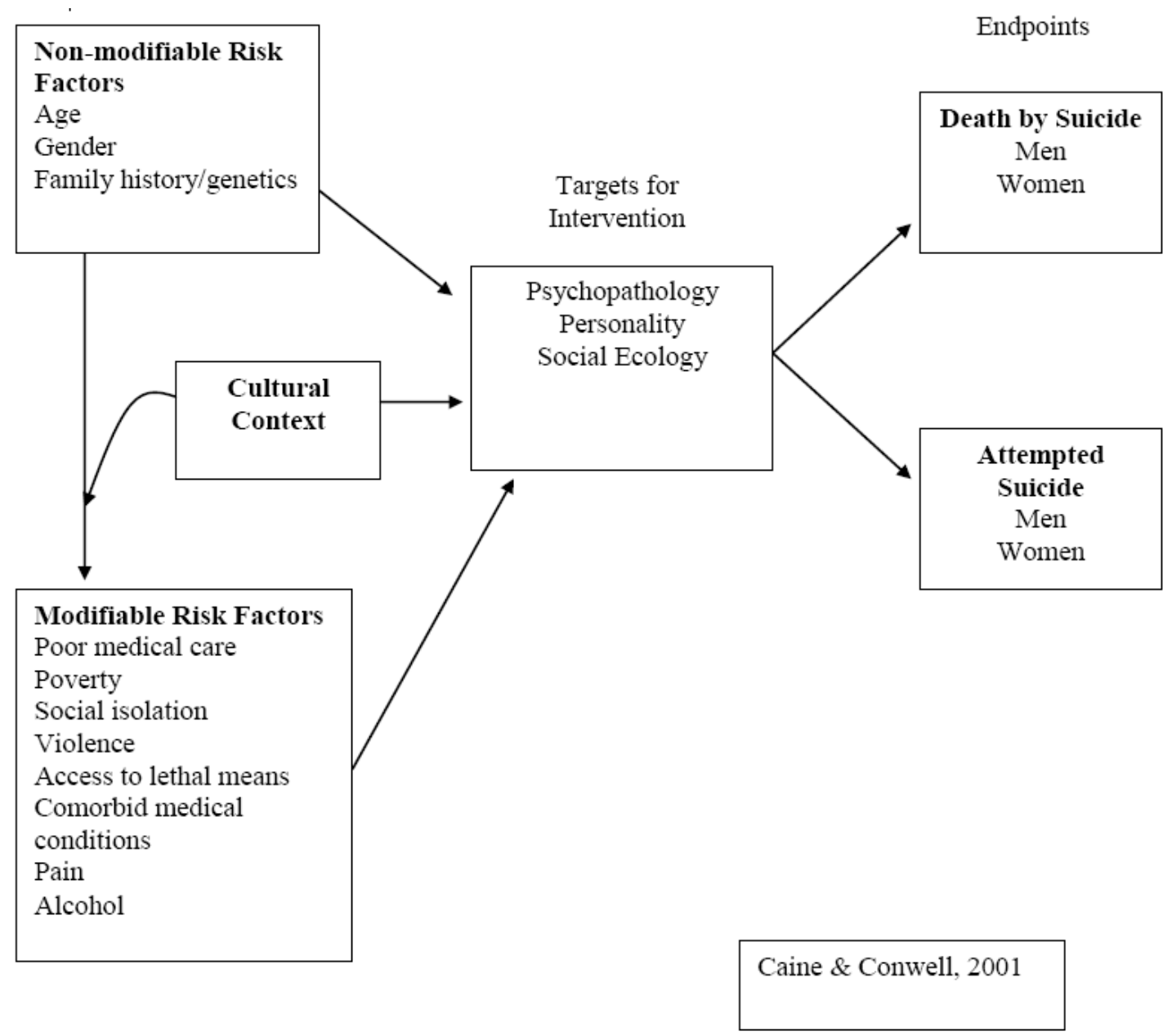




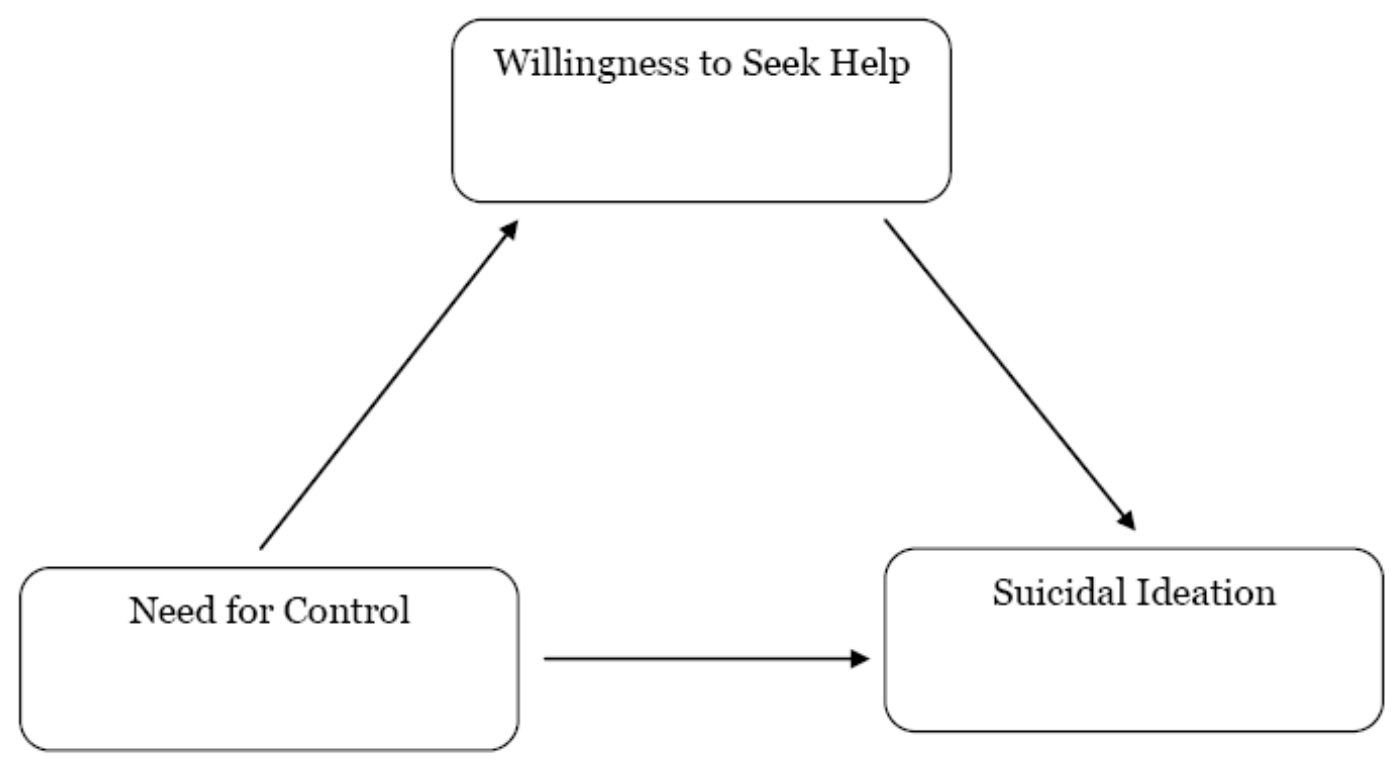




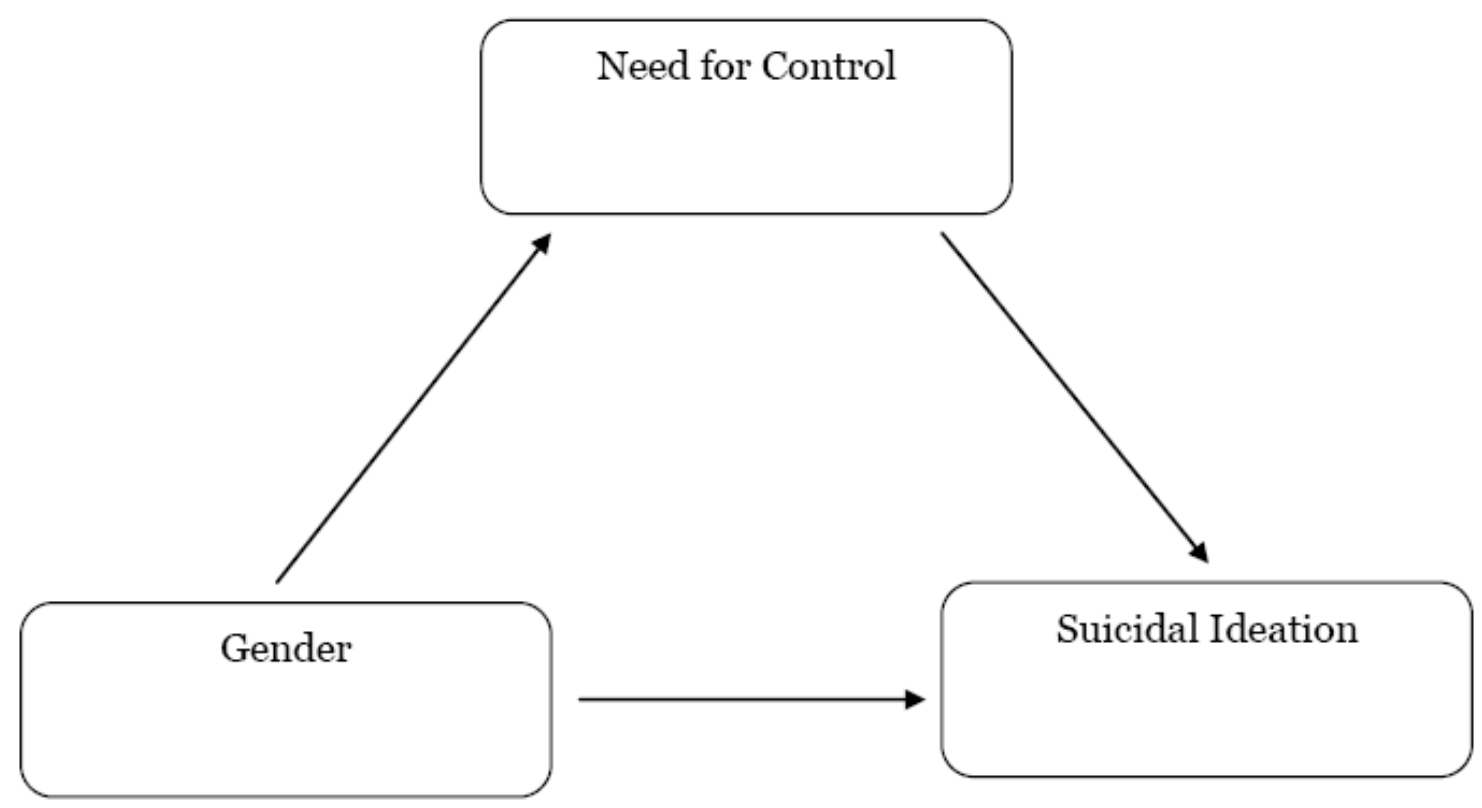

John $\mathrm{H}_{\mathrm{H}}$

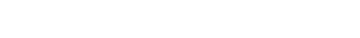

Hagen 